\title{
PD-1/PD-L1 expression and interaction by automated quantitative immunofluorescent analysis show adverse prognostic impact in patients with diffuse large B-cell lymphoma having T-cell infiltration: a study from the International DLBCL Consortium Program
}

\author{
Ling $\mathrm{Li}^{1} \cdot$ Ruifang Sun ${ }^{2} \cdot \mathrm{Yi} \mathrm{Miao}^{1} \cdot$ Thai $^{\mathrm{Tran}^{3}} \cdot$ Lisa Adams $^{3} \cdot$ Nathan Roscoe $^{3} \cdot$ Bing Xu $^{4} \cdot$ Ganiraju C. Manyam $\mathbb{1}^{5}$. \\ Xiaohong Tan ${ }^{1} \cdot$ Hongwei Zhang ${ }^{1} \cdot$ Min Xiao ${ }^{1} \cdot$ Alexandar Tzankov ${ }^{6} \cdot$ Carlo Visco $^{7} \cdot$ Karen Dybkaer $^{8}$. \\ Govind Bhagat $^{9}$ - Wayne Tam ${ }^{10}$ - Eric D. Hsi ${ }^{11}$. J. Han van Krieken ${ }^{12}$ - Hua You ${ }^{13}$. Jooryung Huh ${ }^{14}$ - Maurilio Ponzoni ${ }^{15}$. \\ Andrés J. M. Ferreri ${ }^{15}$. Michael B. Møller $\mathbb{D}^{16}$. Miguel A. Piris ${ }^{17} \cdot$ Mingzhi Zhang $^{18} \cdot$ Jane N. Winter $^{19} \cdot$ L. Jeffrey Medeiros ${ }^{1}$. \\ George Z. Rassidakis ${ }^{20} \cdot$ Christine A. Vaupel $^{3} \cdot$ Yong Li $^{21} \cdot$ Naveen Dakappagari $^{3} \cdot$ Zijun Y. Xu-Monette $^{1} \cdot$ Ken H. Young $^{1,22}$
}

Received: 24 July 2018 / Revised: 21 November 2018 / Accepted: 21 November 2018 / Published online: 21 January 2019

(c) United States \& Canadian Academy of Pathology 2019

\begin{abstract}
Programmed cell death protein 1/programmed cell death protein ligand1 (PD-1/PD-L1) interaction is an important immune checkpoint targeted by anti-PD-1/PD-L1 immunotherapies. However, the observed prognostic significance of PD-1/PD-L1 expression in diffuse large B-cell lymphoma treated with the standard of care has been inconsistent and even contradictory. To clarify the prognostic role of PD-1/PD-L1 expression and interaction in diffuse large B-cell lymphoma, in this study we used 3-marker fluorescent multiplex immunohistochemistry and Automated Quantitative Analysis Technology to assess the $\mathrm{CD}^{+}$, PD-L1 $1^{+}$, and PD- $1^{+} \mathrm{CD}_{3}{ }^{+}$expression in diagnostic samples and PD-1/PD-L1 interaction as indicated by presence of PD- $1^{+} \mathrm{CD} 3^{+}$ cells in the vicinity of PD-L1 ${ }^{+}$cells, analyzed their prognostic effects in 414 patients with de novo diffuse large B-cell lymphoma, and examined whether PD-1/PD-L1 interaction is required for the prognostic role of PD- $1^{+} / \mathrm{PD}-\mathrm{L} 1^{+}$expression. We found that low T-cell tissue cellularity, tissue PD-L1 ${ }^{+}$expression (irrespective of cell types), PD- $1^{+} \mathrm{CD}^{+}$expression, and PD-1/PD-L1 interaction showed hierarchical adverse prognostic effects in the study cohort. PD-1/PD-L1 interaction showed higher sensitivity and specificity than $\mathrm{PD}-1^{+}$and PD-L1 ${ }^{+}$expression in predicting inferior prognosis in patients with high $\mathrm{CD} 3^{+}$tissue cellularity ("hot"/inflammatory tumors). However, both PD-1 $1^{+}$and PD-L1 ${ }^{+}$expression showed adverse prognostic effects independent of PD-1/PD-L1 interaction, and PD-1/PD-L1 interaction showed favorable prognostic effect in PD-L1 ${ }^{+}$patients without high CD3 ${ }^{+}$ tissue cellularity. Macrophage function and tumor-cell MYC expression may contribute to the PD-1-independent adverse prognostic effect of PD- $\mathrm{L}^{+}$expression. In summary, low T-cell tissue cellularity has unfavorable prognostic impact in diffuse large B-cell lymphoma, and tissue PD-L1 ${ }^{+}$expression and T-cell-derived PD- $1^{+}$expression have significant adverse impact only in patients with high T-cell infiltration. PD-1/PD-L1 interaction in tissue is essential but not always responsible for the inhibitory effect of PD-L1 ${ }^{+} / \mathrm{PD}-1^{+}$expression. These results suggest the benefit of PD-1/PD-L1 blockade therapies only in patients with sufficient T-cell infiltration, and the potential of immunofluorescent assays and Automated Quantitative Analysis in the clinical assessment of PD-1/PD-L1 expression and interaction.
\end{abstract}

These authors contributed equally: Ling Li, Ruifang Sun, Yi Miao, Thai Tran, and Zijun Y. Xu-Monette

Supplementary information The online version of this article (https:// doi.org/10.1038/s41379-018-0193-5) contains supplementary material, which is available to authorized users.

Christine A. Vaupel

christine.vaupel@navigatebp.com

$\triangle$ Bing Xu xubingzhangjian@126.com

$\triangle$ Ken H. Young khyoung@mdanderson.org

Extended author information available on the last page of the article

\section{Introduction}

Programmed cell death protein 1 (PD-1) [1] and its ligands PD-L1 [2] and PD-L2 [3] are important immune checkpoint proteins that limit the antitumor response of $\mathrm{T}$ cells. Immunotherapies targeting the PD-1 pathway have shown impressive efficacy in many types of advanced cancers as well as promising clinical activity in refractory or relapsed diffuse large B-cell lymphoma, the most common type of non-Hodgkin lymphoma [4]. However, the differential 
efficacy of anti-PD-1 immunotherapy across different cancer entities is incompletely understood $[5,6]$. Predictive biomarkers are being intensively pursued to guide selection of patients who are more likely to respond to PD-1/PD-L1 blockade, including PD-1/PD-L1 expression (the targets of PD-1/PD-L1 blockade therapy) and T-cell infiltration which were inconsistently associated with higher response rates to anti-PD-1/PD-L1 immunotherapy. There are no known predictive biomarkers for PD-1 blockade in diffuse large B-cell lymphoma currently [5, 6].

Investigating the baseline T-cell infiltration levels and PD-1/PD-L1 expression in a large number of patients with diffuse large B-cell lymphoma can gain insight into the potential of anti-PD-1/PD-L1 immunotherapy in diffuse large B-cell lymphoma. PD-1 can be expressed by both $\mathrm{T}$ cells and lymphoma B cells [7-9]. The primary PD-1 ligand PD-L1 can be expressed on a wide variety of cells. Several study groups have assessed expression of PD-1 [10-13] or PD-L1 [11, 12, 14-17] by single or doublestaining immunohistochemistry in patients with diffuse large B-cell lymphoma. However, most studies have only subjectively assessed PD- $1^{+}$lymphocytes overall or PD$\mathrm{L} 1$ expression on lymphoma cells, but not PD- $1^{+} \mathrm{T}$ cells or PD-L1 expression in the tumor microenvironment, which can also ligate with PD-1 on T cells mediating immune suppression. In addition, PD-1 and PD-L1 expression may be not directly linked to their active interaction and suppressive function. Active PD-1-PD-L1 interaction has been evaluated by proximity between PD-1 and PD-L1, which showed significant association with the efficacy of anti-PD-1 immunotherapy [18] and the survival of patients treated with standard therapy in solid cancer [19]. In Hodgkin lymphoma, recent topological analysis revealed the enrichment of $\mathrm{PD}-\mathrm{L1}^{+}{ }^{+}$(versus $\mathrm{PD}-\mathrm{L1}^{-}$) macrophages and $\mathrm{CD}^{+}$(versus $\left.\mathrm{CD}^{+}\right) \mathrm{T}$ cells in the vicinity of $\mathrm{PD}-\mathrm{L}^{+}{ }^{+}$Hodgkin Reed-Sternberg cells, the spatial enrichment of PD- $1^{+}$or PD- $1^{-} \mathrm{CD} 4^{+} \mathrm{T}$ cells in direct contact (versus without contact) with PD-L1 ${ }^{+}$ Hodgkin Reed-Sternberg cells and tumor-associated macrophages, the spatial enrichment of PD- $1^{+}$or PD $-1^{-} \mathrm{CD} 8^{+}$ $T$ cells in direct contact (versus without contact) with PD$\mathrm{L}^{+}$tumor-associated macrophages, and the characteristics of the tumor microenvironment having high PD-L1 expression from abundant macrophages and low PD-1 expression in T cells [20]. However, whether macrophages and $\mathrm{CD} 4^{+} \mathrm{T}$ cells that are more abundant locally are more functionally relevant for clinical outcome, whether only PD- $1^{+}$cells in direct contact with (but not those distant to) PD-L1 ${ }^{+}$cells are functionally suppressed, and whether only the topologically relevant $\mathrm{PD}-1^{+} / \mathrm{PD}-\mathrm{L} 1^{+}$ cells under microscopy have clinical impact and therapeutic implications in Hodgkin lymphoma have not been studied.
To investigate the prognostic significance of PD-1/PD$\mathrm{L} 1$ expression and interaction in diffuse large B-cell lymphoma, in this study, we employed 3-marker fluorescent multiplex immunohistochemistry to simultaneously analyze tumor-infiltrating $\mathrm{CD}^{+}{ }^{+} \mathrm{T}$ cells, $\mathrm{PD}-1$ expression in tumorinfiltrating $\mathrm{T}$ cells, overall tissue PD-L1 expression, and PD-1/PD-L1 spatial proximity in a large cohort of diffuse large B-cell lymphoma patients. To minimize variation and subjectivity of manual scoring, Automated Quantitative Analysis (AQUA) Technology [21, 22] were used to analyze the local $/ \mathrm{PD}-\mathrm{L}^{+} / \mathrm{PD}-1^{+} / \mathrm{CD}^{+}{ }^{+}$tissue expression and interaction.

\section{Materials and methods}

\section{Patients}

The study cohort included 414 patients with de novo diffuse large B-cell lymphoma with available diagnostic biopsy specimens who were treated with standard immunochemotherapy, consisting of rituximab plus cyclophosphamide, doxorubicin, vincristine, and prednisone (R-CHOP), as part of the International DLBCL Rituximab-CHOP Consortium Program Study. Patients with primary mediastinal large B-cell lymphoma, primary cutaneous diffuse large B-cell lymphoma, primary diffuse large B-cell lymphoma of the central nervous system, HIV-associated diffuse large B-cell lymphoma, or diffuse large B-cell lymphoma transformed from low-grade B-cell lymphoma have been excluded [23]. Gene expression profiling data (GSE\#31312) by the Affymetrix GeneChip Human Genome U133 Plus 2.0 array [24] were available for 361 patients, which classified 328 cases as germinal center B-cell-like or activated B-cell-like subtype. For other cases, cell of origin was determined for 80 cases according to immunohistochemistry analysis using the Visco-Young and/or Choi algorithms [24]. The study was conducted in accordance with the Declaration of Helsinki, and the protocol was approved as being of minimal to no risk or as exempt by the institutional review board of each participating institution.

\section{Quantitative immunofluorescence imaging and analysis}

Tissue microarrays with core size of $1.0 \mathrm{~mm}$ were constructed for diagnostic formalin-fixed, paraffin-embedded tumor samples. Fluorescent staining with CD3 (EP41, Biocare Medical), PD-1 (NAT105, Biocare Medical), and PD-L1 (E1L3N, Cell Signaling Technology) antibodies and 4',6-diamidino-2-phenylindole (DAPI) (cell nuclei) was performed using an automated stainer (Intellipath, Biocare Medical). Fluorescent images were all acquired on the 
Vectra imaging system (PerkinElmer) at $\times 20$ using various channels including DAPI (blue), Cy5 (red), Cy3.5 (orange), and Opal 520 (green).

Vectra images were analyzed by proprietary analysis algorithms $\mathrm{AQUA}^{\circledast}{ }^{\circledR}$ (Navigate BioPharma Services, Inc) [21]. Cell population analysis was performed by establishing cell masks that represent all cells and individual cell types in the tissue microarray cores. All cell compartments were derived by converting DAPI signals to binary images and then dilated to approximate size of an entire cell. CD3, PD1, and PD-L1 cells were identified by creating binary masks without dilation, as membrane staining outlines actual cell size. CD3/PD-1 double-positive cells were established by identifying overlap areas between CD3 and PD-1 binary cell compartments. In colored multiplexed images, overlapping regions show overlaid color. For example, colocalization of green and red colors produces a degree of yellow color. To evaluate PD-1/PD-L1 interaction, PD-L1 binary masks were first dilated to create an interaction mask encompassing the nearest neighbor cells. Interaction scores were then generated by calculating overlap areas between the PD $-1^{+} / \mathrm{CD}^{+}$ compartment and the dilated PD-L1 mask multiplied by 10,000 to create whole numbers representing an interaction score for each specimen.

\section{Statistical analysis}

Clinicopathologic parameters were compared between groups using the Fisher's exact test. Overall survival was calculated from the date of diagnosis to the date of last follow-up or death. Progression-free survival was calculated from the date of diagnosis to the date of disease progression or death. Survival of patients was compared by Kaplan-Meier curves and the log-rank (Mantel-Cox) test. $P$ values of $\leq 0.05$ were considered statistically significant. As multiple comparisons were performed, the significance was adjusted by both the Benjamini-Hochberg procedure and the Bonferroni correction methods. Gene expression profiling analysis was performed by the R software. Differential expressed genes were identified by multiple $t$ tests and the obtained $P$ values were corrected for multiple testing controlling the false discovery rate as described previously $[24,25]$.

\section{Results}

\section{T-cell infiltration and tissue PD-L1/PD-1 expression and interaction in diffuse large B-cell lymphoma}

Figure 1 shows immunofluorescent staining images for two representative samples of diffuse large B-cell lymphoma. Numbers of $\mathrm{CD}^{+}$, PD- $1^{+}$, PD-L1 $1^{+}$, and PD- $1^{+} \mathrm{CD}^{+}$(i.e., $\mathrm{PD}-1^{+} \mathrm{T}$ ) cells in the entire tissue area were simultaneously

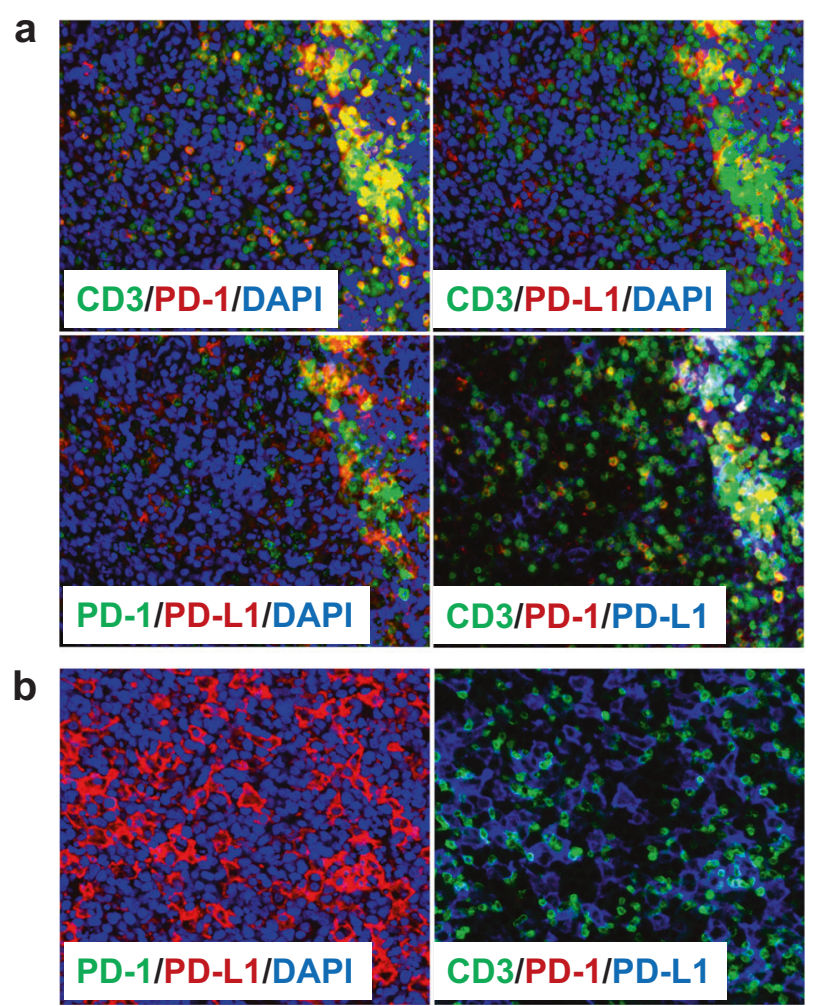

Fig. 1 Representative images of $\mathrm{CD}^{+}, \mathrm{PD}^{+} 1^{+}$, and PD-L1 ${ }^{+}$expression in diffuse large B-cell lymphoma samples by fluorescent multiplex immunohistochemistry (counter-stained with DAPI). a A representative case with $\mathrm{PD}-1^{+} \mathrm{T}$ cells proximal to $\mathrm{PD}-\mathrm{L} 1^{+}$cells in the tissue specimen. Cells with PD- $1^{+}$(red fluorescence) and $\mathrm{CD}^{+}$(green fluorescence; T-cell marker) co-expression show yellow color in the color imaging overlay. b A representative case having $\mathrm{PD}-\mathrm{L}^{+}{ }^{+}$cells but no PD $-1^{+} \mathrm{T}$ cells in the tissue

quantified. PD- ${ }^{+} \mathrm{T}$ cells within the vicinity of PD-L1 compartment were identified and evaluated by a PD-1/PDL1 interaction score. CD3/PD-1/PD-L1 expression levels were assessed by total tissue cellularity, dividing the positive cell numbers by total nucleated cells $($ DAPI + ) and rounding to the nearest $0.1 \%$. Most (90\%) lymphoma cases had T-cell infiltration with a mean tissue cellularity of $13.6 \%$. PD-L1 was expressed in 53\% of the cohort, and in these cases, PD-L1 was expressed by a mean tissue cellularity of $6.7 \%$. PD-1 was expressed in $30 \%$ of lymphoma cases, and in these cases, PD-1 was expressed by a mean tissue cellularity of $1.46 \%$. T-cell-specific PD-1 expression was detected in $18 \%$ of lymphoma cases with a mean tissue cellularity of $1.1 \%$. In $20 \%$ of the cohort, PD- 1 was also expressed on $\mathrm{CD}^{-}$cells with a mean tissue cellularity of $1.24 \%$. Interaction scores were in the range of $0-3910$. About $23 \%$ of cases had a positive interaction score, with a mean score of 190 . The mean tissue cellularity of $\mathrm{CD}^{+}$, PD-L1 ${ }^{+}, \mathrm{PD}-1^{+}$, and PD- $1^{+} \mathrm{CD}^{+}$cells in the entire cohort were $12.1 \%, 3.6 \%, 0.44 \%$, and $0.19 \%$, respectively. Activated B-cell-like compared with germinal center B-celllike diffuse large B-cell lymphoma had a significantly 
higher mean tissue cellularity of $\mathrm{PD}-\mathrm{L} 1^{+}$cells $(P=$ 0.0013; Supplementary Figure 1a), but not $\mathrm{CD}^{+}$cells or $\mathrm{PD}-1^{+} \mathrm{CD}^{+}$cells.

\section{Hierarchical unfavorable prognostic effects associated with tissue cellularity of $\mathrm{CD}^{+}, \mathrm{PD}-1^{+}$ $\mathrm{CD}^{+}$, and PD-L1 ${ }^{+}$cells}

CD3/PD-1/PD-L1 expression and PD-1/PD-L1 interaction scores were correlated with patient survival. In the overall diffuse large B-cell lymphoma cohort, patients with a low percentage of $\mathrm{CD}^{+} \mathrm{T}$ cells in the tumor tissue $\left(\mathrm{CD}^{-/ l o}\right.$, $0 \%$ to $3.5 \%$ of all cells were $\mathrm{CD}^{+}$) had a poorer overall survival rate compared with patients with a high $\mathrm{CD}^{+}$ tissue cellularity $\left(\mathrm{CD} 3^{\mathrm{hi}},>3.5 \%\right.$ of all cells were $\left.\mathrm{CD} 3^{+}\right)$ $(P=0.02$; Fig. 2a). Patients with a positive tissue cellularity of $\mathrm{PD}-\mathrm{L} 1^{+}$cells or PD- $1^{+} \mathrm{T}$ cells had a non-significantly poorer progression-free survival rate $(P=0.057$ and $P=$ 0.079 , respectively) but a similar overall survival rate compared with cases with a negative tissue cellularity. The distribution of cases with $\mathrm{CD} 3^{\text {hi }}$, PD-L $1^{+}$, or PD- $1^{+} \mathrm{CD} 3^{+}$ tissue cellularity or with PD-1/PD-L1 interaction in the cohort is shown in Fig. $2 b$.

Although the $\mathrm{CD} 3^{\text {hi }}$ group was prognostically favorable compared with the $\mathrm{CD}^{-/ \mathrm{lo}}$ group, it had higher mean cellularity of PD-L1 ${ }^{+}$cells and PD- $1^{+} \mathrm{CD}^{+}$cells $(P<0.0001$ and $P=0.0002$, respectively; Supplementary Figure $1 \mathrm{~b}$ ), which remained significant after exclusion of $\mathrm{CD}^{-}$cases
(0\% tissue cellularity) from the $\mathrm{CD} 3^{-/ \mathrm{lo}}$ group (that is, $\mathrm{CD} 3^{\text {lo }}$ subset) $(P<0.0001$ and $P=0.0007$, respectively). Moreover, in the $\mathrm{CD} 3^{\mathrm{hi}}$ group of patients, the presence of PD- $1^{+}$ tumor-infiltrating $\mathrm{T}$ cells was associated with significantly poorer overall survival $(P=0.028$; Supplementary Figure 1c) and progression-free survival $(P=0.0099$, Fig. 2 c), although $\mathrm{PD}-1^{+} \mathrm{CD}^{+}$cases had a higher T-cell tissue cellularity $(P<0.0001)$. $\mathrm{PD}-\mathrm{L}^{+}$cellularity was also associated with significantly poorer overall survival $(P=0.0063$; Fig. 2d) and progression-free survival $(P=0.0058$; Supplementary Figure 1c) in the $\mathrm{CD} 3^{\text {hi }}$ group, but it was not associated with higher $\mathrm{CD}^{+}$tissue cellularity $(P=0.3)$. Similarly, positive PD-1/PD-L1 interaction scores, suggesting interaction between PD-1 ${ }^{+} \mathrm{T}$ cells and PD-L1 ${ }^{+}$cells, were associated with significantly poorer overall survival $(P=0.0006$; Fig. 2e) and progression-free survival $(P=$ 0.0003; Supplementary Figure 1c) in the $\mathrm{CD} 3^{\text {hi }}$ patients, despite the association with a higher $\mathrm{CD}^{+}$tissue cellularity $(P=0.0012)$. In contrast, the presence of $\mathrm{PD}-1^{+} \mathrm{CD} 3^{-}$cells was not prognostic in $\mathrm{CD} 3^{\text {hi }}$ patients $(P=0.99$ for overall survival and $P=0.95$ for progression-free survival) or the entire cohort.

When $\mathrm{CD} 3^{\text {hi }}$ cases were divided into germinal center B-cell-like and activated B-cell-like subtypes, the adverse prognostic effects associated with $\mathrm{PD}-1^{+} / \mathrm{PD}-\mathrm{L1}^{+}$expression in patients with $\mathrm{CD} 3^{\text {hi }}$ tissue cellularity were only significant in the activated B-cell-like diffuse large B-cell lymphoma subset, whereas PD-1/PD-L1 interaction was a

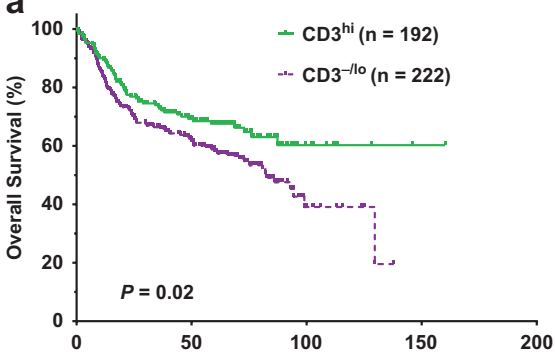

b

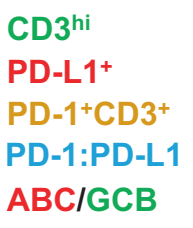

\section{4 diffuse large B-cell lymphoma cases}

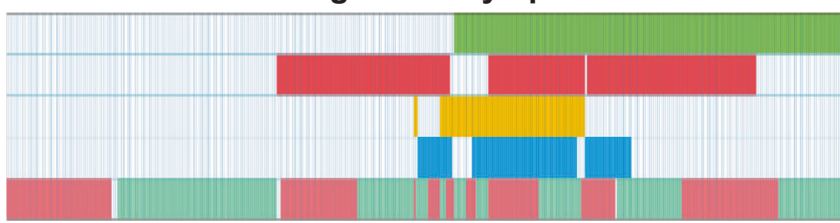

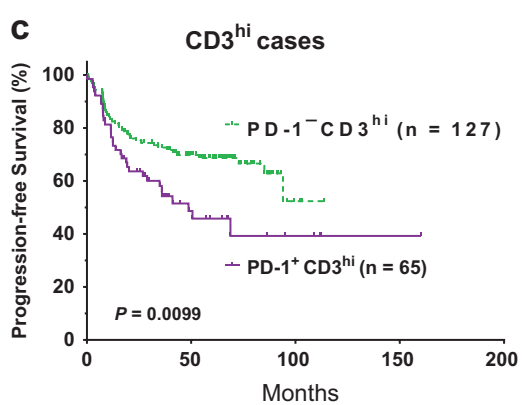

Fig. 2 Prognostic analysis for CD3, PD-L1, and T-cell-derived PD-1 expression in the study cohort. a High tissue cellularity of $\mathrm{CD}^{+}$ $\mathrm{T}$ cells was associated with significantly better overall survival in patients with diffuse large B-cell lymphoma. b A plot illustrating the case distribution of $\mathrm{CD} 3^{\mathrm{hi}}, \mathrm{PD}-\mathrm{L} 1^{+}$, and $\mathrm{PD}-1^{+} \mathrm{CD} 3^{+}$tissue cellularity and PD-1/PD-L1 proximity (PD-1:PD-L1 interaction). Each column
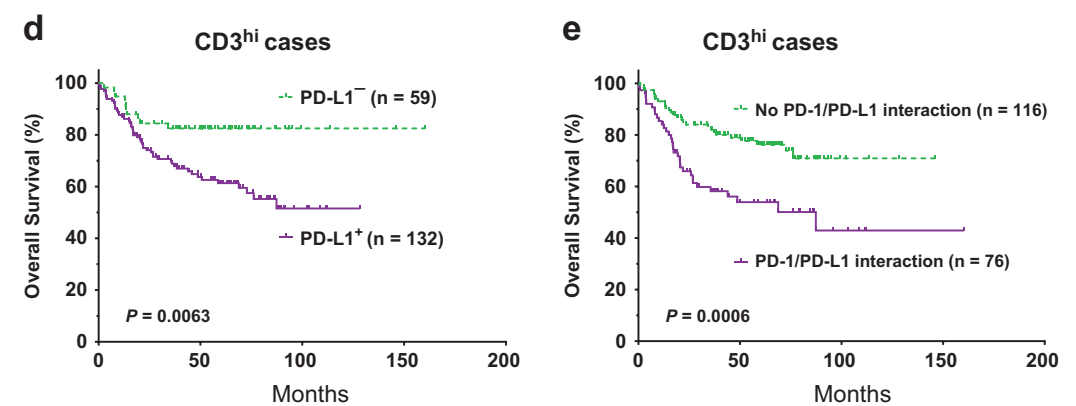

represents one patient. Positive cases were indicated by corresponding colors. Abbreviations: ABC, activated B-cell-like; GCB, germinal center B-cell-like. $\mathbf{c}$ In $\mathrm{CD} 3^{\text {hi }}$ cases, PD-1 expression on $\mathrm{T}$ cells was associated with significantly poorer progression-free survival. d-e In $\mathrm{CD} 3^{\text {hi }}$ cases, PD-L1 expression and positive PD-1/PD-L1 interaction scores were associated with significantly poorer overall survival 
associated with significantly poorer overall survival in both germinal center B-cell-like $(P=0.024)$ and activated B-cell-like subtypes $(P=0.01)$ as well as poorer progression-free survival in the activated B-cell-like subtype $(P=0.0007$; Supplementary Figure $1 \mathrm{~d})$.

Clinical features were compared between groups of patients with different prognosis. Patients with $\mathrm{CD}^{-/ l o}$ cellularity more often had $>1$ extranodal site of involvement and an International Prognostic Index score of $>2$ (Table 1). PD-L1 expression was associated with primary nodal and an advanced stage of disease and elevated serum lactate dehydrogenase level in the overall cohort (Table 1) and with advanced stage, B-symptom, and an International Prognostic Index score of $>2$ in the $\mathrm{CD} 3^{\text {hi }}$ subcohort. $\mathrm{PD}-1^{+} \mathrm{CD} 3^{+}$ expression in $\mathrm{CD} 3^{\mathrm{hi}}$ patients was associated with a performance status score $>1$ (Table 1). PD-1/PD-L1 interaction in $\mathrm{CD} 3^{\text {hi }}$ patients was associated with an International Prognostic Index score of $>2$, advanced stage, a performance status score of $>1$, and $>1$ extranodal site of involvement (Supplementary Table 1).

\section{Independent adverse prognostic effects of PD-1 ${ }^{+} \mathrm{CD}^{+}$ and PD-L1 ${ }^{+}$expression and PD-1/PD-L1 interaction in CD3 ${ }^{\text {hi }}$ patients}

Because the presence of PD- $1^{+} \mathrm{T}$ cells was associated with a higher mean PD- $1^{+}$tissue cellularity in the overall diffuse large B-cell lymphoma cohort $(P<0.0001$; Supplementary Figure $1 \mathrm{e})$ and the $\mathrm{CD} 3^{\text {hi }}$ subset $(P=0.019)$, we examined the dependency of the prognostic effects associated with PD- $1^{+} \mathrm{CD}^{+}$expression and PD-L $1^{+}$expression in patients with $\mathrm{CD} 3^{\text {hi }}$ cellularity. We found that compared with patients having neither PD-1 nor PD-L1 expression, patients with PD- $1^{+}$T cells had significantly poorer overall/ progression-free survival regardless of positive/negative PD-L1 expression (PD- $1^{+} \mathrm{CD}^{+} / \mathrm{PD}-\mathrm{L}^{+}{ }^{+}$patients: $P=$ 0.0002 for overall survival and $P<0.0001$ for progressionfree survival; PD- $1^{+} \mathrm{CD}^{+} / \mathrm{PD}-\mathrm{L} 1^{-}$patients: $P=0.012$ for overall survival and $P=0.016$ for progression-free survival; Fig. 3a and Supplementary Figure 2a). PD $-1^{+} \mathrm{CD}^{+}$ expression also had significant adverse prognostic effect regardless of presence/absence of PD-1/PD-L1 interaction (Fig. $3 b$ and Supplementary Figure 2b).

Conversely, in $\mathrm{CD}^{\text {hi }}$ patients with $\mathrm{PD}-1^{+} \mathrm{CD}^{+}$ expression, PD-L1 expression and PD-1/PD-L1 interaction were not associated with a significant prognostic effect. However, in $\mathrm{CD} 3^{\text {hi }}$ patients without $\mathrm{PD}-1^{+} \mathrm{CD} 3^{+}$expression $\left(\mathrm{PD}-1^{-} \mathrm{CD} 3^{\mathrm{hi}}\right)$, $\mathrm{PD}-\mathrm{L} 1^{+}$expression was associated with significantly poorer overall survival $(P=0.0034$; Fig. 3c) and progression-free survival $(P=0.0059$; Supplementary Figure S2a), independent of whether the tumors were of germinal center B-cell-like or activated B-cell-like subtype. Although this suggests that PD-L1 had inhibitory function independent of PD-1 expression on T cells, PD-L1 positivity was not associated with higher PD- $1^{+}$expression on non-T $\left(\mathrm{CD}^{-}\right)$cells $\left(P=0.23\right.$ for decrease) or $\mathrm{CD}^{+}{ }^{+} \mathrm{T}$ cellularity $(P=0.81)$. The inferior survival may not result from interaction with PD-1 expressed on non-T cells also because the presence of PD- $1^{+} \mathrm{CD}^{-}$cells was not prognostic in $\mathrm{PD}-1^{-} \mathrm{CD} 3^{\text {hi }}$ patients. On the other hand, we surprisingly found that a small number of $\mathrm{PD}-\mathrm{L}^{+}{ }^{+}$/ PD- $1^{-} \mathrm{CD} 3^{\text {hi }}$ cases $(n=23$; Fig. $2 \mathrm{~b})$ had a low but positive PD-1/PD-L1 interaction score (1-53), suggesting presence of low numbers of PD- $1^{+} \mathrm{T}$ cells $(<0.1 \%$ tissue cellularity) having active interaction with $\mathrm{PD}-\mathrm{L}^{+}$cells. Presence of (albeit low) PD-1/PD-L1 interaction had significantly poorer survival in the PD- $1^{-} \mathrm{CD} 3^{\text {hi }}$ subcohort $(P<0.0001$ for OS, $P=0.0001$ for progression-free survival; Fig. $3 \mathrm{~d}$ and Supplementary Figure 2b), independent of the germinal center B-cell-like $(P=0.0005$ for overall survival and $P=0.0058$ for progression-free survival) and activated Bcell-like subtypes $(P=0.033$ for overall survival and $P=$ 0.014 for progression-free survival). Furthermore, PD-1/ PD-L1 interaction significantly contributed to the adverse prognostic effect of $\mathrm{PD}-\mathrm{L}^{+}{ }^{+}$expression in $\mathrm{PD}-1^{-} \mathrm{CD} 3^{\text {hi }}$ patients, as it was associated with significantly poorer survival in $\mathrm{PD}-1^{-} \mathrm{CD} 3^{\text {hi }}$ cases with PD-L1 ${ }^{+}$expression $(P$ $=0.0083$ for both overall survival and progression-free survival; Fig. 3e). Nonetheless, after cases with positive PD-1/PD-L1 interaction scores were excluded, PD-L1 expression remained to be associated with significantly poorer survival ( $P=0.032$ for OS; Fig. 3 f and $P=0.049$ for progression-free survival).

We looked for prognostic biomarkers differentially associated with PD-L1 expression according to PD-1 expression status in diffuse large B-cell lymphoma. We found that in the $\mathrm{PD}-1^{-} \mathrm{CD} 3^{\text {hi }}$ subcohort, but not in the $\mathrm{CD} 3{ }^{\text {hi }}$ subcohort with $\mathrm{PD}-1^{+} \mathrm{CD} 3^{+}$expression, PD-L1 ${ }^{+}$ expression was significantly associated with a higher mean level of tumor Myc expression $(P=0.015$; Fig. 4a), a higher frequency (19\% vs. $2 \%, P=0.011)$ of $\mathrm{Myc} / \mathrm{Bcl}-2$ dual expression $\left(\mathrm{MYC}^{+} \mathrm{BCL2}^{+}\right.$, an adverse prognostic factor $[23,25,26])$, and a lower frequency of CD30 positivity [27] ( $14 \%$ vs. $29 \%, P=0.05)$ evaluated by standard immunohistochemistry. $\mathrm{CD} 30^{-}$was also associated with PD- $1^{+} \mathrm{CD}^{+}$expression and PD-1/PD-L1 interaction in $\mathrm{CD} 3^{\text {hi }}$ cases (Table 1 and Supplementary Table 1). After exclusion of cases with positive PD-1/PD-L1 interaction scores from the PD $-1^{-} \mathrm{CD} 3^{\text {hi }}$ cases, the association of PD$\mathrm{L1}^{+}$with Myc overexpression remained significant $(P=$ 0.041; Fig. 4b). PD-L1 expression in these patients and in the overall $\mathrm{PD}-1^{-} \mathrm{CD} 3^{\text {hi }}$ cases was also associated with activated B-cell-like subtype and female sex (Supplementary Table 1 ).

The association of $\mathrm{MYC}^{+} \mathrm{BCL} 2^{+}$cases significantly contributed to the adverse prognostic effect of PD-L1 
Table 1 Clinicopathologic characteristics of studied patients with de novo diffuse large B-cell lymphoma $(n=414)$

\begin{tabular}{|c|c|c|c|c|c|c|c|c|c|}
\hline \multirow[t]{2}{*}{ Characteristic } & \multirow{2}{*}{$\begin{array}{l}\mathrm{CD}^{-/ \mathrm{lo}} \\
n(\%)\end{array}$} & \multirow{2}{*}{$\begin{array}{l}\mathrm{CD}^{\text {hi }} \\
n(\%)\end{array}$} & \multirow[b]{2}{*}{$P$} & \multirow{2}{*}{$\begin{array}{l}\mathrm{PD}^{\mathrm{L}} 1^{+} \\
n(\%)\end{array}$} & \multirow{2}{*}{$\begin{array}{l}\text { PD-L1- } \\
n(\%)\end{array}$} & \multirow[b]{2}{*}{$P$} & \multirow{2}{*}{$\begin{array}{l}\mathrm{PD}-1 \\
{ }^{+} \mathrm{CD} 3^{\mathrm{hi}} \\
n(\%)\end{array}$} & \multirow{2}{*}{$\begin{array}{l}\mathrm{PD}-1^{-} \mathrm{CD} 3^{\mathrm{L}} \\
n(\%)\end{array}$} & \multirow[b]{2}{*}{$P$} \\
\hline & & & & & & & & & \\
\hline \multicolumn{10}{|l|}{ Age } \\
\hline$<60$ years & $97(44)$ & $88(46)$ & 0.69 & $96(44)$ & $88(45)$ & 0.84 & $31(48)$ & $57(45)$ & 0.76 \\
\hline$\geq 60$ years & $125(56)$ & $104(54)$ & & $122(56)$ & $106(55)$ & & $34(52)$ & $70(55)$ & \\
\hline \multicolumn{10}{|l|}{ Sex } \\
\hline Male & $130(59)$ & $112(58)$ & 1.0 & $120(55)$ & $121(62)$ & 0.13 & $37(57)$ & $75(59)$ & 0.88 \\
\hline Female & $92(41)$ & $80(42)$ & & $98(45)$ & $73(38)$ & & $28(43)$ & $52(41)$ & \\
\hline \multicolumn{10}{|l|}{ Stage } \\
\hline I-II & $92(43)$ & $89(47)$ & 0.55 & $84(39)$ & $96(51)$ & 0.027 & $26(41)$ & $63(50)$ & 0.28 \\
\hline III-IV & $121(57)$ & $102(53)$ & & $129(61)$ & $93(49)$ & & $38(59)$ & $64(50)$ & \\
\hline \multicolumn{10}{|l|}{ B-symptoms } \\
\hline No & $132(63)$ & $121(64)$ & 0.92 & $124(60)$ & $127(68)$ & 0.12 & $36(56)$ & 85 (69) & 0.11 \\
\hline Yes & $76(37)$ & $67(36)$ & & $83(40)$ & $60(32)$ & & $28(44)$ & $39(31)$ & \\
\hline \multicolumn{10}{|c|}{ Serum LDH levels } \\
\hline Normal & $67(34)$ & $72(40)$ & 0.20 & $59(30)$ & $79(45)$ & 0.003 & $22(35)$ & $50(43)$ & 0.34 \\
\hline Elevated & $132(66)$ & $106(60)$ & & $140(70)$ & $97(55)$ & & $41(65)$ & $65(57)$ & \\
\hline \multicolumn{10}{|c|}{ No. of extranodal sites } \\
\hline $0-1$ & $146(70)$ & $150(80)$ & 0.02 & $158(75)$ & $137(75)$ & 1.0 & $45(71)$ & $105(85)$ & 0.051 \\
\hline$\geq 2$ & $63(30)$ & $37(20)$ & & $53(25)$ & $46(25)$ & & $18(29)$ & $19(15)$ & \\
\hline \multicolumn{10}{|c|}{ ECOG performance status } \\
\hline $0-1$ & $152(79)$ & $149(85)$ & 0.14 & $155(78)$ & $144(86)$ & 0.078 & $48(77)$ & $101(89)$ & 0.045 \\
\hline$\geq 2$ & $41(21)$ & $26(15)$ & & $43(22)$ & $24(14)$ & & $14(23)$ & $12(11)$ & \\
\hline \multicolumn{10}{|c|}{ Size of largest tumor } \\
\hline$<5 \mathrm{~cm}$ & $95(59)$ & $91(56)$ & 0.57 & $86(52)$ & $99(63)$ & 0.056 & $30(53)$ & $61(58)$ & 0.62 \\
\hline$\geq 5 \mathrm{~cm}$ & $65(41)$ & $72(44)$ & & $78(48)$ & $58(37)$ & & $27(47)$ & $45(42)$ & \\
\hline \multicolumn{10}{|l|}{ IPI risk group } \\
\hline $0-2$ & $113(54)$ & $123(65)$ & 0.026 & $118(55)$ & $117(63)$ & 0.15 & $39(60)$ & $84(67)$ & 0.34 \\
\hline $3-5$ & $98(46)$ & $67(35)$ & & $95(45)$ & $69(37)$ & & $26(40)$ & $41(33)$ & \\
\hline \multicolumn{10}{|c|}{ Therapy response } \\
\hline $\mathrm{CR}$ & $159(72)$ & $153(80)$ & 0.067 & $163(75)$ & $148(76)$ & 0.73 & $50(77)$ & $103(81)$ & 0.57 \\
\hline Non-CR & $63(28)$ & $39(20)$ & & $55(25)$ & $46(24)$ & & $15(23)$ & 24 (19) & \\
\hline \multicolumn{10}{|l|}{ Cell of origin } \\
\hline GCB & $116(53)$ & $96(50)$ & 0.55 & $90(42)$ & $121(63)$ & $<0.001$ & $33(51)$ & $63(50)$ & 1.0 \\
\hline $\mathrm{ABC}$ & $101(47)$ & $95(50)$ & & $125(58)$ & $70(37)$ & & $32(49)$ & $63(50)$ & \\
\hline \multicolumn{10}{|c|}{$\mathrm{Myc}^{+}$expression } \\
\hline Low & $140(65)$ & $141(75)$ & 0.051 & $146(68)$ & $134(72)$ & 0.51 & $49(78)$ & $92(73)$ & 0.60 \\
\hline High & $74(35)$ & $48(25)$ & & $68(32)$ & $53(28)$ & & $14(22)$ & $34(27)$ & \\
\hline $\mathrm{MYC}^{+} \mathrm{BCL}^{+}$ & & & & & & & & & \\
\hline No & $173(80)$ & $163(87)$ & 0.065 & $176(82)$ & $159(85)$ & 0.51 & $55(89)$ & $108(86)$ & 0.65 \\
\hline Yes & $44(20)$ & $25(13)$ & & $39(18)$ & $29(15)$ & & $7(11)$ & $18(14)$ & \\
\hline CD30 express & & & & & & & & & \\
\hline Negative & $177(82)$ & $161(86)$ & 0.35 & $178(83)$ & $159(85)$ & 0.79 & $61(94)$ & $100(81)$ & 0.027 \\
\hline Positive & $39(18)$ & 27 (14) & & $36(17)$ & $29(15)$ & & $4(6)$ & 23 (19) & \\
\hline
\end{tabular}

$L D H$ lactate dehydrogenase, ECOG Eastern Cooperative Oncology Group, IPI International Prognostic Index, $C R$ complete remission, $G C B$ germinal center B-cell-like, $A B C$ activated B-cell-like

Significant $P$ values and border-line 0.051 are in bold 
a

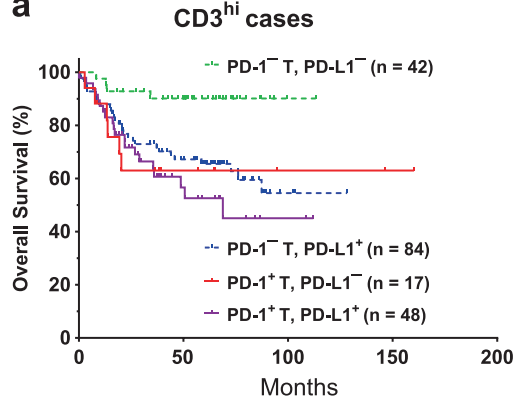

b

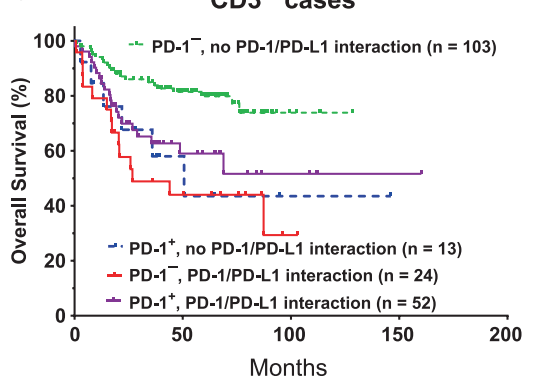

c

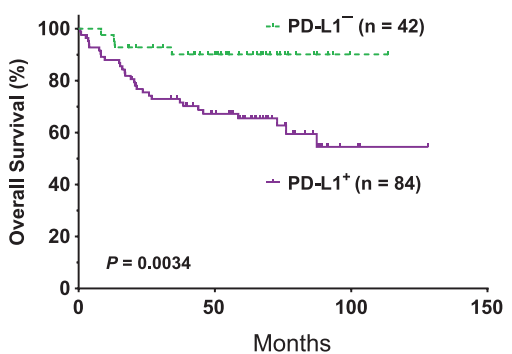

d

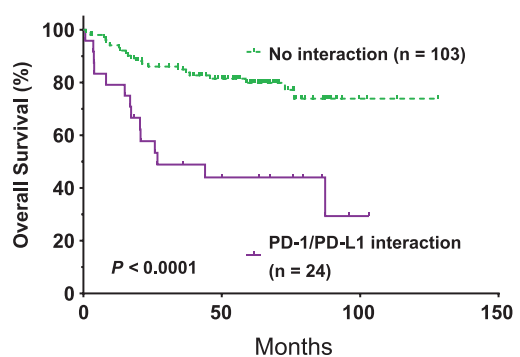

e

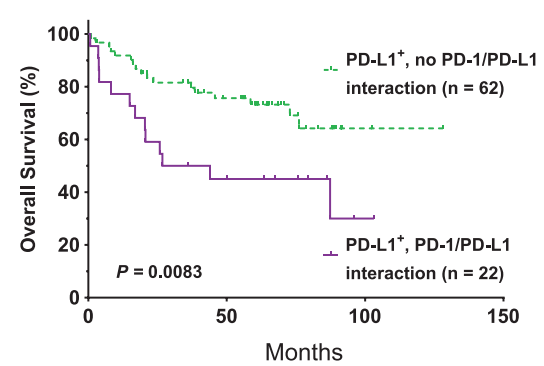

$\mathbf{f}$

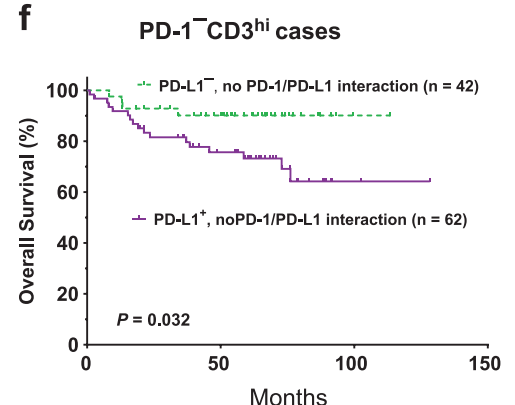

Fig. 3 Independent prognostic effects of PD-1 and PD-L1 expression and the role of PD-1/PD-L1 interaction in patients with high $\mathrm{CD}^{+}$ tissue cellularity $\left(\mathrm{CD} 3^{\text {hi }}\right.$ cases). a In $\mathrm{CD} 3^{\text {hi }}$ cases, PD-1 expression in $\mathrm{T}$ cells was associated with significantly poorer overall survival with or without PD-L1 expression. b In CD $3^{\text {hi }}$ cases, PD-1 expression were associated with significantly poorer overall survival with or without a positive PD-1/PD-L1 interaction score. $\mathbf{c}$ In CD $3^{\text {hi }}$ cases without PD-1 $1^{+}$

expression in the $\mathrm{PD}-1^{-} \mathrm{CD} 3^{\text {hi }}$ group, in that $\mathrm{MYC}^{+} \mathrm{BCL} 2^{+}$ expression was associated with significantly poorer overall survival and progression-free survival both in PD $-1^{-} \mathrm{CD} 3^{\text {hi }}$ patients overall and in patients with $\mathrm{PD}-\mathrm{L} 1^{+} / \mathrm{PD}-1^{-} \mathrm{CD} 3^{\text {hi }}$ cellularity (Fig. 4c) (all $P<0.0001$ ). Nonetheless, after exclusion of cases with $\mathrm{MYC}^{+} \mathrm{BCL} 2^{+}$expression from the $\mathrm{PD}-1^{-} \mathrm{CD} 3^{\text {hi }}$ cases, PD-L1 expression remained to be associated with significantly poorer progression-free survival $(P=0.013$; Fig. $4 \mathrm{~d})$, and a trend toward poorer overall survival also was seen $(P=0.074)$. After exclusion of both $\mathrm{MYC}^{+} \mathrm{BCL}^{+}$cases and cases with a positive PD-1/PD-L1 interaction score from the PD $-1^{-} \mathrm{CD} 3^{\text {hi }}$ subcohort, PD-L1 expression was not associated with overall survival or progression-free survival in $\mathrm{PD}-1^{-} \mathrm{CD} 3^{\text {hi }}$ cases $(P=0.18$ and $P=0.29$ for poorer overall survival and progressionfree survival, respectively).

\section{Unfavorable prognostic effect of PD-L1 ${ }^{+}$expression and favorable prognostic effect of PD-1/PD-L1 interaction in $\mathrm{CD}^{-/ 10}$ patients}

In patients with $\mathrm{CD}^{-/ \mathrm{lo}}$ tissue cellularity, presence of PD-1/ PD-L1 interaction (positive score 1-3366) was associated with a higher mean $\mathrm{CD} 3^{+}$and $\mathrm{PD}-1^{+} \mathrm{CD} 3^{+}$tissue cellularity (all $P<0.0001$ ), and non-significantly better overall survival $(P=0.065$; Supplementary Figure $2 \mathrm{c})$ and progression-free expression (PD-1 ${ }^{-} \mathrm{CD} 3^{\text {hi }}$ ), PD-L1 expression were associated with significantly poorer overall survival. d-e Positive PD-1/PD-L1 interaction scores were associated with significantly poorer overall survival in all PD- $1^{-} \mathrm{CD} 3^{\text {hi }}$ cases and in PD- $1^{-} \mathrm{CD} 3^{\text {hi }}$ cases with PD-L1 ${ }^{+}$ expression. $\mathbf{f}$ After exclusion of cases with a positive PD-1/PD-L1 interaction score, $\mathrm{PD}-\mathrm{L}^{+}$expression remained to be associated with significantly poorer overall survival in $\mathrm{PD}-1^{-} \mathrm{CD} 3^{\text {hi }}$ cases

survival $(P=0.08)$. In the subset of $\mathrm{CD}^{-/ \mathrm{lo}}$ patients with PD-L1 ${ }^{+}$tissue cellularity, PD-1/PD-L1 interaction was associated with significantly better overall survival $(P=$ 0.014, Fig. 4e) and progression-free survival $(P=0.011$; Supplementary Figure 2d), especially in the activated B-celllike subtype of diffuse large B-cell lymphoma $(P=0.038$ for overall survival and $P=0.0088$ for progression-free survival; Supplementary Figure 3a).

Like PD-1/PD-L1 interaction, PD- $1^{+} \mathrm{CD}^{+}$expression in the $\mathrm{CD} 3{ }^{\text {lo }}$ patients was associated with a higher mean $\mathrm{CD}^{+}$ cellularity $(P=0.014)$, but the expression was not prognostic either in the $\mathrm{CD}^{-/ \mathrm{lo}}$ or $\mathrm{CD} 3^{\text {lo }}$ subset. PD-L1 expression was also significantly associated with a higher mean $\mathrm{CD}^{+}$tissue cellularity in both the $\mathrm{CD} 3^{-/ \mathrm{lo}}$ and $\mathrm{CD} 3^{\text {lo }}$ groups $(P<0.0001$ and $P=0.0006$, respectively), as well as activated $\mathrm{B}$-cell-like subtype $(P=0.036)$, elevated serum lactate dehydrogenase level $(P=0.0011)$, primary nodal disease $(P=0.0041)$, and CD30 positivity (25\% vs. $13 \%$, $P=0.043)$. After patients with PD-1/PD-L1 interaction (favorable) and patients with $\mathrm{MYC}^{+} \mathrm{BCL}^{+}$expression (unfavorable, $P<0.0001$ ) were excluded from the $\mathrm{CD}^{-/ \mathrm{lo}}$ subcohort, PD-L1 expression was associated with significantly poorer overall survival $(P=0.02$, Fig. $4 f)$ and progression-free survival $(P=0.018$; Supplementary Figure $3 \mathrm{~b}$ ), even though $\mathrm{PD}-\mathrm{L1}^{+}$expression was still associated with higher $\mathrm{CD}^{+}$tissue cellularity $(P=0.0003)$. 


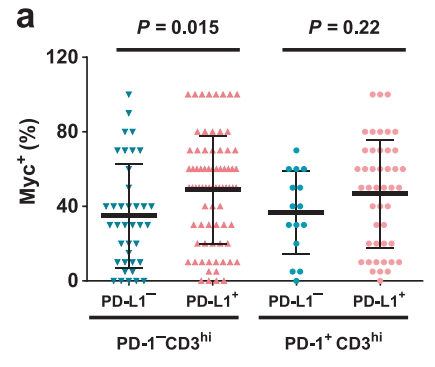

C
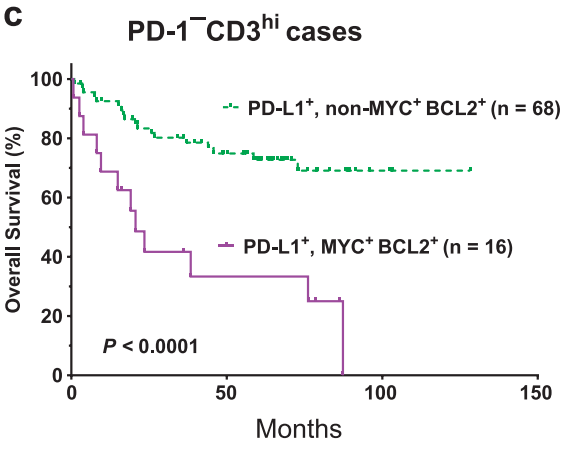

b

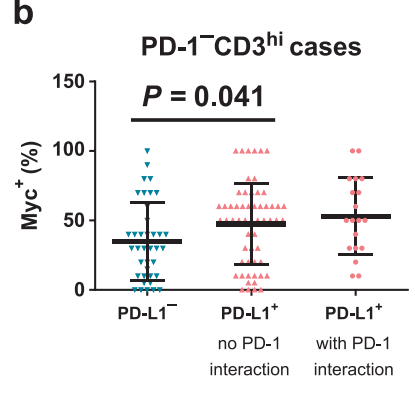

d

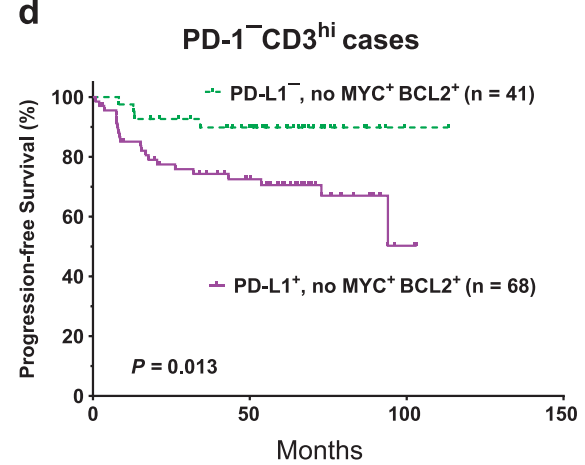

e

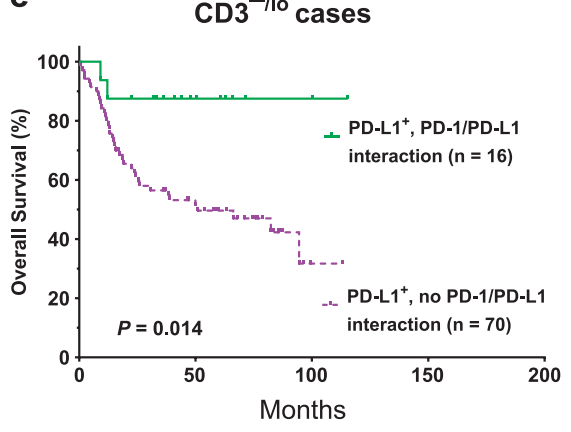

f $\mathrm{CD}^{-110}$ cases, non-MYC ${ }^{+} \mathrm{BCL2}^{+}$, no PD-1/PD-L1 interaction

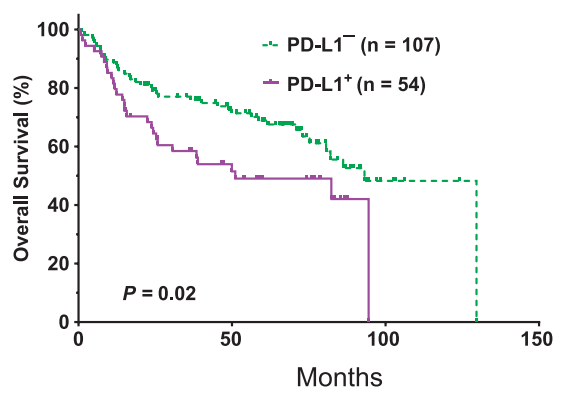

Fig. 4 Tumor-cell Myc expression and survival analysis in cases with PD- $1^{-} \mathrm{CD} 3^{\text {hi }}$ tissue cellularity (PD- $1^{-} \mathrm{CD} 3^{\text {hi }}$ cases). a-b In PD $-1^{-} \mathrm{CD} 3^{\text {hi }}$ cases, PD-L1 ${ }^{+}$expression was associated with a higher mean level of Myc expression by traditional immunohistochemistry. $\mathbf{c}$ In PD- $1^{-} \mathrm{CD} 3^{\text {hi }}$ cases with PD-L1 ${ }^{+}$expression, $\mathrm{MYC}^{+} \mathrm{BCL}^{+}$double-expression was associated with significantly poorer overall survival. d After exclusion of $\mathrm{MYC}^{+} \mathrm{BCL}^{+}{ }^{+}$double-expressors from PD-1-CD3 ${ }^{\text {hi }}$ cases, PD-L1

\section{Multiple testing correction and multivariate survival analysis}

Significance of multiple comparisons in the study cohort was adjusted using both the BenjaminiHochberg procedure and Bonferroni correction (Supplementary Table 2). By the Benjamini-Hochberg procedure with a false discovery rate of 0.10 , the adverse prognostic effect of $\mathrm{CD}^{-/ \mathrm{lo}}$ cellularity in overall cohort, the adverse prognostic effects of PD-L1 expression, PD-1 expression, and PD-1/PD-L1 interaction in $\mathrm{CD} 3^{\text {hi }}$ cases, the adverse prognostic effect of PD-L1 expression in the $\mathrm{CD}^{-/ \mathrm{lo}}$ subset without PD-1 interaction and $\mathrm{MYC}^{+} \mathrm{BCL}_{2}{ }^{+}$expression, and the favorable prognostic effect of PD-1/PD-L1 interaction in cases with $\mathrm{PD}-\mathrm{L} 1^{+} / \mathrm{CD}^{-/ \mathrm{lo}}$ tissue cellularity all remained significant. By the more stringent Bonferroni criterion for six tests, only the adverse prognostic effects of PD-1/PD-L1 interaction and PD-L1 expression in CD $3^{\text {hi }}$ cases were significant.

Multivariate survival analyses were performed to adjust for clinical parameters using the Cox regression model. In the overall cohort, the favorable effect of $\mathrm{CD} 3^{\text {hi }}$ cellularity on overall survival was not significant $(P=0.11$, hazard ratio (HR) $0.74,95 \%$ confidence interval (CI) 0.52-1.07); expression remained to be associated with significantly poorer progression-free survival. e In cases with $\mathrm{PD}-\mathrm{L}^{+} / \mathrm{CD}^{-/ \mathrm{lo}}$ tissue cellularity, PD-1/PD-L1 interaction was associated with significantly better overall survival. f After exclusions of cases with PD-1/PD-L1 interaction and cases with $\mathrm{MYC}^{+} \mathrm{BCL} 2^{+}$expression from the $\mathrm{CD} 3^{-/ l o}$ subcohort, $\mathrm{PD}-\mathrm{L1}^{+}$expression was associated with significantly poorer overall survival marginally significant $P$ values of poorer progression-free survival were seen for PD-L1 ${ }^{+}$expression $(P=0.068$, HR $1.39,95 \%$ CI $0.98-1.97)$ and PD-1/PD-L1 interaction $(P=$ 0.072 , HR $1.42,95 \%$ CI 0.97-2.09). However, in the CD $3^{\text {hi }}$ (but not $\mathrm{CD}^{- \text {llo }}$ ) subcohort, PD-1/PD-L1 interaction and $\mathrm{PD}-\mathrm{L}^{+}$expression were identified as significant adverse prognostic factors independent of clinical factors (Table 2). Although PD- $1^{+}$expression was not an independent prognostic factor in the multivariate analysis, the adverse prognostic effects of PD-1/PD-L1 interaction and PD-L1 ${ }^{+}$ expression in $\mathrm{CD} 3^{\text {hi }}$ patients were significant only in patients with $\mathrm{PD}-1^{-} \mathrm{CD} 3^{\text {hi }}$ tissue cellularity (Table 2) but not in $\mathrm{CD} 3^{\text {hi }}$ patients with $\mathrm{PD}-1^{+} \mathrm{CD} 3^{+}$expression.

After further adding the activated B-cell-like risk factor into the Cox regression models, only PD-1/PD-L1 interaction remained as an independent prognostic factor in $\mathrm{CD} 3^{\text {hi }}$ patients $(P=0.009$, HR $2.01,95 \%$ CI $1.19-3.41$ for progression-free survival and $P=0.046$, HR $1.79,95 \% \mathrm{CI}$ 1.01-3.16 for OS). PD-L1 expression only showed a marginal $P$ value for being an independent factor for poorer progression-free survival with the additional adjustment of cell of origin $(P=0.08$, data not shown). 
Table 2 Multivariate survival analysis for tissue PD-1/PD-L1 expression and interaction in diffuse large B-cell lymphoma treated with R-CHOP

\begin{tabular}{|c|c|c|c|c|c|c|}
\hline & & OS & & & PFS & \\
\hline & HR & $95 \% \mathrm{CI}$ & $P$ & HR & $95 \% \mathrm{CI}$ & $P$ \\
\hline \multicolumn{7}{|c|}{ DLBCL with CD3 $^{\text {hi }}$ tissue cellularity } \\
\hline PD-L1 ${ }^{+}$ & 1.66 & $0.79-3.49$ & 0.18 & 2.21 & $1.06-4.57$ & 0.034 \\
\hline B-symptoms & 0.84 & $0.45-1.54$ & 0.57 & 0.96 & $0.55-1.68$ & 0.88 \\
\hline Tumor size $\geq 5 \mathrm{~cm}$ & 1.39 & $0.80-2.42$ & 0.25 & 1.11 & $0.67-1.86$ & 0.68 \\
\hline Female sex & 1.22 & $0.68-2.17$ & 0.51 & 1.00 & $0.58-1.74$ & 0.99 \\
\hline IPI >2 & 3.20 & $1.80-5.69$ & $<0.001$ & 2.95 & $1.74-5.00$ & $<0.001$ \\
\hline \multicolumn{7}{|c|}{ DLBCL with CD3 $^{\text {hi }}$ tissue cellularity } \\
\hline PD-1 $^{+} \mathbf{C D 3}^{+}$ & 1.45 & $0.82-2.57$ & 0.20 & 1.50 & $0.90-2.52$ & 0.12 \\
\hline B-symptoms & 0.97 & $0.55-1.70$ & 0.90 & 0.84 & $0.46-1.54$ & 0.58 \\
\hline Tumor size $\geq 5 \mathrm{~cm}$ & 1.17 & $0.70-1.94$ & 0.55 & 1.40 & $0.80-2.43$ & 0.24 \\
\hline Female sex & 1.14 & $0.67-1.95$ & 0.63 & 1.33 & $0.75-2.36$ & 0.32 \\
\hline IPI $>2$ & 3.10 & $1.83-5.25$ & $<0.001$ & 3.30 & $1.86-5.86$ & $<0.001$ \\
\hline \multicolumn{7}{|c|}{ DLBCL with CD3 $^{\text {hi }}$ tissue cellularity } \\
\hline $\begin{array}{l}\text { PD-1/PD-L1 } \\
\text { interaction }\end{array}$ & 1.78 & $1.01-3.16$ & 0.048 & 2.03 & $1.20-3.44$ & 0.008 \\
\hline B-symptoms & 1.25 & $0.75-2.11$ & 0.40 & 0.99 & $0.57-1.72$ & 0.96 \\
\hline Tumor size $\geq 5 \mathrm{~cm}$ & 1.11 & $0.68-1.82$ & 0.68 & 1.13 & $0.68-1.88$ & 0.64 \\
\hline Female sex & 1.04 & $0.62-1.73$ & 0.88 & 1.18 & $0.69-2.01$ & 0.55 \\
\hline IPI >2 & 2.92 & $1.76-4.85$ & $<0.001$ & 2.83 & $1.66-4.81$ & $<0.001$ \\
\hline \multicolumn{7}{|c|}{ DLBCL with PD-1 CD3 ${ }^{\text {hi }}$ tissue cellularity } \\
\hline PD-L1 ${ }^{+}$ & 3.49 & $1.19-10.2$ & 0.023 & 4.11 & $1.42-11.9$ & 0.009 \\
\hline B-symptoms & 0.60 & $0.25-1.44$ & 0.25 & 0.77 & $0.35-1.71$ & 0.53 \\
\hline Tumor size $\geq 5 \mathrm{~cm}$ & 2.14 & $1.00-4.55$ & 0.049 & 1.42 & $0.70-2.88$ & 0.33 \\
\hline Female sex & 0.95 & $0.44-2.05$ & 0.89 & 0.91 & $0.44-1.91$ & 0.81 \\
\hline IPI $>2$ & 4.25 & $2.00-9.03$ & $<0.001$ & 4.05 & $2.00-8.17$ & $<0.001$ \\
\hline \multicolumn{7}{|c|}{ DLBCL with PD-1 CD3 ${ }^{\text {hi }}$ tissue cellularity } \\
\hline $\begin{array}{l}\text { PD-1/PD-L1 } \\
\text { interaction }\end{array}$ & 3.75 & $1.68-8.38$ & 0.001 & 4.31 & $1.95-9.53$ & $<0.001$ \\
\hline B-symptoms & 0.89 & $0.38-2.07$ & 0.78 & 1.32 & $0.59-2.98$ & 0.50 \\
\hline Tumor size $\geq 5 \mathrm{~cm}$ & 2.37 & $1.11-5.05$ & 0.025 & 1.52 & $0.76-3.04$ & 0.23 \\
\hline Female sex & 1.35 & $0.63-2.88$ & 0.44 & 1.43 & $1.55-6.42$ & 0.33 \\
\hline IPI >2 & 3.05 & $1.41-6.61$ & 0.005 & 3.16 & $3.10-61.8$ & 0.001 \\
\hline
\end{tabular}

$R$-CHOP rituximab with cyclophosphamide, doxorubicin, vincristine, and prednisone, $O S$ overall survival. $P F S$ progression-free survival, $H R$ hazard ratio, $C I$ confidence interval, IPI International Prognostic Index. Only factors of PD-L1/PD-1 expression and interaction and their significant $P$ values are in bold.

\section{Gene signatures associated with T-cell infiltration and PD-1/PD-L1 expression}

Gene expression profiling data were analyzed to identify signatures associated with $\mathrm{CD} 3^{\text {hi }}$ cellularity in the overall cohort and with $\mathrm{PD}-1^{+} \mathrm{CD}^{+}$expression and $\mathrm{PD}-\mathrm{L} 1^{+}$ expression in the $\mathrm{CD} 3^{\text {hi }}$ and $\mathrm{CD} 3^{-/ \mathrm{lo}}$ subcohorts.

Patients with $\mathrm{CD} 3^{\text {hi }}$ tissue cellularity was associated with a distinct gene signature, including upregulation of genes involved in the T-cell receptor complex (TRBC1, CD $3 E$, and TRAT1), adhesion (ITM2A, SIRPG, and CD2), chemotaxis (CXCL9 and CXCL1O), T-cell cytolytic function (GZMK, GZMA, GBP1, and GBP2), cell survival (BCL11B and GIMAP1), SLAMF7 (a receptor regulating a wide variety of immune cells), and complement component
$C 1 Q B$ (Fig. 5a, Table 3; false discovery rate $<0.01$, fold change $>1.74)$ ).

For PD- $1^{+}$expression in $\mathrm{T}$ cells, gene signatures were identified in the $\mathrm{CD}^{+}, \mathrm{CD}^{\text {hi }}$, and $\mathrm{PD}-\mathrm{L}^{+} / \mathrm{CD} 3^{\text {hi }}$ subcohorts, but not in the PD-L1 ${ }^{-} / \mathrm{CD}^{\text {hi }}$ subcohort. NFATC2, a transcription factor regulating $P D C D 1$ expression, was upregulated in PD-L $1^{+} / \mathrm{CD} 3^{\text {hi }}$ patients with $\mathrm{PD}-1^{+} \mathrm{CD}^{+}$expression (Supplementary Figure 3c, Table 3). Presence of PD-1/ PD-L1 interaction showed a gene signature in the activated Bcell-like subtype but not in the germinal center B-cell-like subtype of $\mathrm{CD} 3^{\text {hi }}$ cases (Supplementary Figure 3d, Table 3), which included upregulation of ubiquitin ligases (FBXO36 and $R B C K 1$ ) and genes involved in biosynthesis and metabolism, and downregulation of PTCH1 (receptor for Hedgehog) and genes involved in biosynthesis (ST6GALNAC5), actin organization $(R A B 3 I P)$, membrane trafficking (ZFYVE16), and protein folding (RICS).

For PD-L1 ${ }^{+}$expression, the gene signature identified in $\mathrm{CD} 3^{\text {hi }}$ patients included some genes shared with the $\mathrm{CD} 3^{\text {hi }}$ gene signature (such as CXCL9/10, GZMK/A, GBPI/2, $S L A M F 7$, and $C 1 Q B$ ) and some unique genes including CXCL11, CCL8, PRF1, KLRK1, FCGR1B, FCERIG, $S T A T 1$, and LILRB2 (Fig. 5b, false discovery rate $<0.01$ ). In the PD- $1^{-} \mathrm{CD} 3^{\text {hi }}$ subset, PD-L1 ${ }^{+}$expression was associated with upregulation of genes with T-cell cytolytic function (PRF1), complement (CIQB, FCGRIB, and CIQA), and $M T D H$ (which activates NF-кB), and downregulation of the transcription factor TEADl with tumor suppression function and adhesion genes (FLRT2 and ITGAG) (Table 3). After exclusion of cases with a positive PD-1/PD-L1 interaction score from the PD- $1^{-} \mathrm{CD} 3^{\text {hi }}$ subset, PD-L1 ${ }^{+}$expression was associated with a gene signature featuring upregulating of the macrophage markers $C D 163$ and $C D 68$ and monocyte chemoattractant genes CCL8, CXCL10, and CXCL11 (Fig. 5b, Table 3).

No gene signature was identified for PD-L1 ${ }^{+} / \mathrm{PD}-1^{+}$ expression or interaction in $\mathrm{CD}^{-/ \mathrm{lo}}$ patients overall, but a distinct gene signature was identified for $\mathrm{PD}-\mathrm{L}^{+}$expression in the $\mathrm{CD}^{-}$activated B-cell-like subset, including upregulation of MYOIG, CDRT1, IL8RB, adhesion genes, and metabolism genes (Supplementary Figure 3e, Table 3).

\section{Discussion}

Unlike previous studies that separately quantified PD-1 ${ }^{+}$ lymphocytes of any cell type and $\mathrm{PD}-\mathrm{L}^{+}{ }^{+}$percentage of tumor cells with traditional chromogen-based immunohistochemistry, this study simultaneously quantified $\mathrm{CD}^{+}$cells, PD- $1^{+} \mathrm{CD} 3^{+} \mathrm{T}$ cells, and total PD-L $1^{+}$cells of any cell type as well as the PD-1/PD-L1 interaction score in the same tissue microarray cores using a 3-marker 4-color fluorescent multiplex immunohistochemistry platform. PD-1/PD-L1 
a

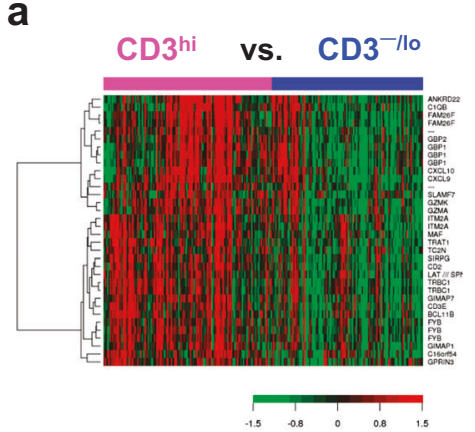

b

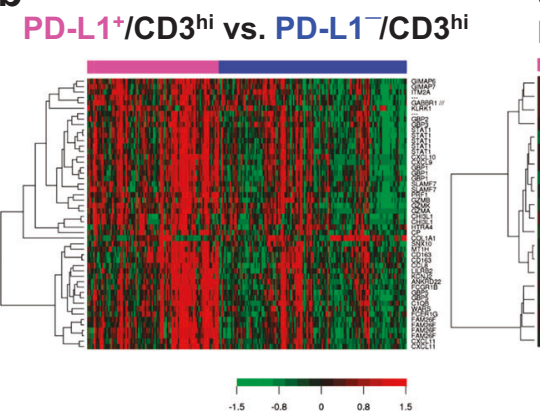

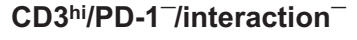
$\mathrm{PD}-\mathrm{L1}^{-}$vs. PD-L1+

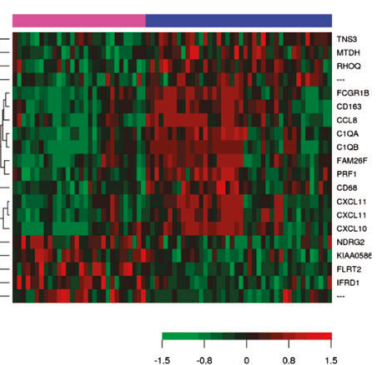

C

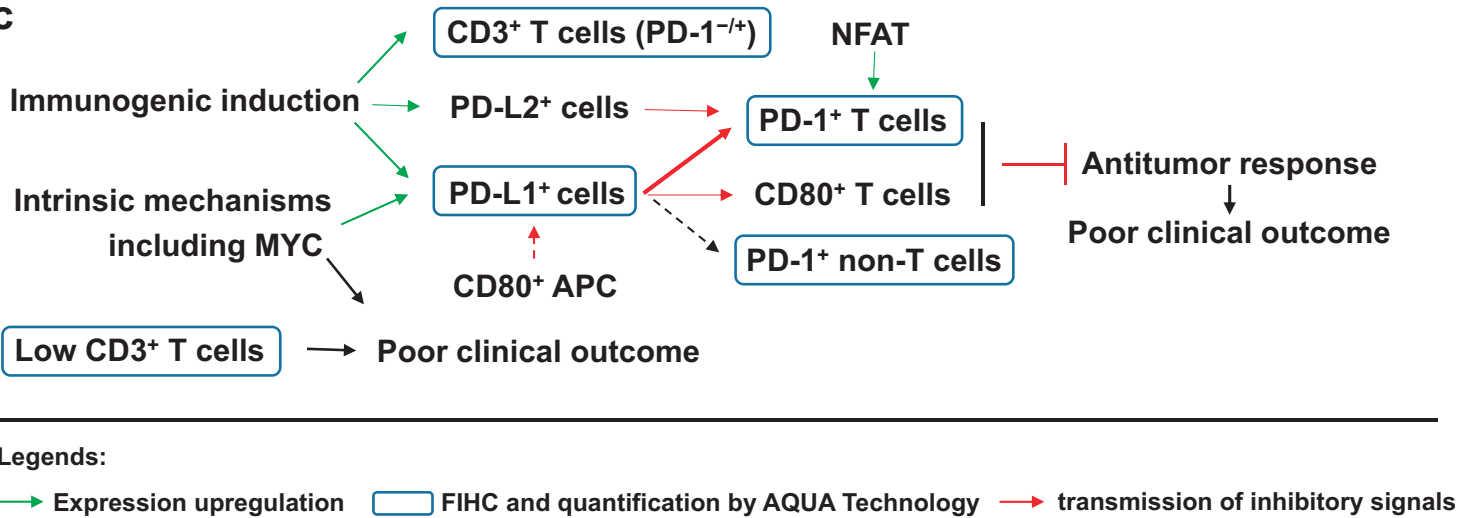

Fig. 5 Gene expression profiling analysis and a schematic summary for this study. a Heatmap for differentially expressed genes between $\mathrm{CD}^{-/ l o}$ and $\mathrm{CD} 3^{\text {hi }}$ cases (false discovery rate threshold: 0.01 ; fold change cutoff: > 1.74). b Heatmap for differentially expressed genes between PD- $1^{+}$and PD-L1 ${ }^{-}$patients in the $\mathrm{CD} 3^{\text {hi }}$ cases overall (false discovery rate threshold: 0.01 ; fold change cutoff: $>1.7$ ) and in the PD- $1^{-}$CD $3^{\text {hi }}$ subset without PD-1/PD-L1 interaction (false discovery rate threshold: 0.30). c A schematic diagram illustrating the relevant regulation, interaction, and prognostic effects of PD-L1/CD3/PD-1 expression in this study or according to the literature. Green arrows

interaction was also assessed with an interaction score, which increase with the proportion of PD- $1^{+} \mathrm{T}$ cells proximal to PD-L1 ${ }^{+}$cells. Computerized AQUA was used to quantitate expression and interaction, in order to provide more continuous and reproducible measures of PD-1/PD-L1 expression in terms of biomarker intensity, percent positivity, and receptor-ligand interactions. Gene expression profiling data, which was not available in earlier studies, were analyzed for gene signatures associated with CD3/PD-1/PD-L1 expression and PD-1/L1 interaction. The results demonstrated the capability of a fully automated process to stratify patients with diffuse large B-cell lymphoma treated with R-CHOP, and a significant hierarchical association of low intratumoral $\mathrm{T}$ cells, PD- $1^{+}$expression in $\mathrm{T}$ cells, overall $\mathrm{PD}-\mathrm{L}^{+}{ }^{+}$expression, and PD-1/PD-L1 interaction in the tissue with poorer survival. First, absence to a low tumor-infiltrating $\mathrm{CD}^{+}{ }^{+} \mathrm{T}$-cell tissue cellularity was associated with worse overall survival and a gene expression profiling signature indicating lower antitumor T-cell response. Second, high $\mathrm{CD}^{+}{ }^{+} \mathrm{T}$-cell tissue cellularity was associated with increased PD-1/PD-L1 expression, and indicate upregulation of PD-1/PD-L1 expression; red arrows indicate transmission of inhibitory signals by receptor/ligand interaction; dashed red or black arrow indicates uncertain inhibitory or unknown effects; red bar-headed line indicates inhibition; blue boxes highlight the detection of expression by fluorescent multiplex immunohistochemistry and AQUA in diffuse large B-cell lymphoma specimens; and black arrows indicate prognostic effects. Abbreviation: APC, antigen-presenting cells; FIHC, fluorescent multiplex immunohistochemistry; AQUA, Automated Quantitative Analysis

the expression and interaction of PD-L1/PD-1 had adverse prognostic effects in patients with $\mathrm{CD} 3^{\text {hi }}$ tissue cellularity. Third, both PD- $1^{+}$and PD-L1 ${ }^{+}$expression had adverse prognostic impact independent of PD-1/PD-L1 interaction, likely attributable to the presence of other inhibitory interactions (such as with PD-L2 and CD80) [28-30] and other mechanisms (Fig. 5c).

In earlier studies, presence of PD- $1^{+}$lymphocyte was paradoxically associated with favorable or no differential survival in diffuse large B-cell lymphoma overall [6]. In a more recent study, Kiyasu et al. [14] showed that PD-L1 ${ }^{\text {hi }}$ percentage of tumor cells but not PD- $1^{+}$lymphocyte numbers had significant adverse effect on OS, resembling the no effect of T-cell PD- $1^{+}$expression on overall survival in overall patients identified through fluorescent coexpression in this study. However, $\mathrm{PD}-1^{+} \mathrm{CD} 3^{+}$expression showed a nonsignificant trend of poorer progression-free survival in the overall cohort. Moreover, by separating the prognostic effect of T-cell infiltration from that of PD- $1^{+}$ expression, this study clearly demonstrated the unfavorable 
Table 3 Gene expression signatures associated with high $\mathrm{CD}^{+}$tissue cellularity or positive $\mathrm{PD}-1^{+} / \mathrm{PD}-\mathrm{L} 1^{+}$expression and interaction

\begin{tabular}{|c|c|c|}
\hline Comparisons & Upregulated genes & Downregulated genes \\
\hline $\mathrm{CD}^{\text {hi }}$ vs. $\mathrm{CD} 3^{-1 \mathrm{lo}}$ & $\begin{array}{l}(\mathrm{FDR}<0.01, \text { fold change }>1.74 *) \text { CXCL9, GZMK, ITM2A, } \\
\text { FAM26F, TRBC1, GZMA, CD3E, GBP1, C16orf54, GIMAP7, } \\
\text { SIRPG, MAF, GPRIN3, TRAT1, BCL11B, FYB, GIMAP1, CD2, } \\
\text { CXCL10, LAT/ SPNS1, FYB, ANKRD22, SLAMF7, TC2N, GBP2, } \\
\text { C1QB }\end{array}$ & \\
\hline In $\mathrm{CD}^{\text {hi }}$ cases, $\mathrm{PD}^{-\mathrm{L} 1^{+}}$vs. $\mathrm{PD}-\mathrm{L1}^{-}$ & $\begin{array}{l}\text { (FDR }<0.01 \text {, fold change }>1.7 * \text { ) CXCL9, FAM26F, GBP1, } \\
\text { CXCL10, GZMK, CHI3L1, CCL8, C1QB, GZMA, ANKRD22, } \\
\text { PRF1, GZMB, FCGR1B, CXCL11, SLAMF7, MT1H, SNX10, } \\
\text { GBP5, CP, GBP2, CDI63, GIMAP7, STAT1, KCNJ2, GABBR1/ } \\
\text { UBD, KLRK1, GBP3, WARS, FCERIG, LILRB2, GIMAP6, } \\
\text { HTRA4, ITM2A }\end{array}$ & COL1A1 \\
\hline $\begin{array}{l}\text { In PD-1 } 1^{-} \mathrm{CD} 3^{\text {hi }} \text { cases, } \mathrm{PD}-\mathrm{L} 1^{+} \text {vs. PD- } \\
\mathrm{L}^{-}{ }^{-}\end{array}$ & $(\mathrm{FDR}<0.20) C 1 Q B, F C G R 1 B, P R F 1, C 1 Q A, R H O Q, M T D H$ & $\begin{array}{l}\text { EMID1, FLRT2, ITPKB, SH3D19, ITGA6, TTC9, } \\
\text { TEAD1, LOC285972 }\end{array}$ \\
\hline $\begin{array}{l}\text { In PD- } 1^{-} \mathrm{CD} 3^{\text {hi }} \text { cases excluding cases } \\
\text { with PD-1/PD-L1 interaction, PD-L1 }{ }^{+} \\
\text {vs. PD-L1 }{ }^{-}\end{array}$ & $\begin{array}{l}(\mathrm{FDR}<0.30) \text { CCL8, C1QB, CXCL10, FCGR1B, FAM26F, } \\
\text { CD163, CXCL11, C1QA, PRF1, RHOQ, TNS3, CD68, MTDH }\end{array}$ & FLRT2, IFRD1, NDRG2, KIAA0586 \\
\hline $\begin{array}{l}\text { In PD-L1 } 1^{+} \mathrm{CD} 3^{\text {hi }} \text { cases, } \mathrm{PD}-1^{+} \mathrm{CD} 3^{+} \\
\text {vs. PD- }{ }^{-} \mathrm{CD}^{+}\end{array}$ & $\begin{array}{l}(\mathrm{FDR}<0.10) \text { LOC439949, UTRN, TFPI, RAB27A, ZBED2, } \\
\text { FAM160B1, OXNAD1, CNIH4, NFATC2, PPP3CC, PTP4A2, } \\
\text { PRKAG2, USP33, DHCR24 }\end{array}$ & $\begin{array}{l}\text { ZNF275, RAB7L1, CNR1, TCTE3, PNPLA5, FLJ23834, } \\
\text { AFP, POU3F1, KLHL1, NUDT12, LOC285423, } \\
\text { Clorf114 }\end{array}$ \\
\hline $\begin{array}{l}\text { In } \mathrm{CD}^{+} \text {cases, } \mathrm{PD}-1^{+} \mathrm{CD}^{+} \text {vs. PD- } \\
1^{-} \mathrm{CD}^{+}\end{array}$ & $\begin{array}{l}(\mathrm{FDR}<0.15) \text { ITM2A, C16orf54, CD3E, GZMK, TRAT1, GZMA, } \\
\text { TRBC1, TC2N, SH2D1A, GPRIN3, LOC439949, IPCEF1, } \\
\text { CUGBP2, CD2, GIMAP6, CST7, CD3D, BCL11B, RAB27A, } \\
\text { ATP9A, AKAP7, PRKCH, LIFR, CYLD, APOL6, CD27, } \\
\text { FLJ16686, N4BP2L1, CCR2 }\end{array}$ & FOXD4 \\
\hline $\begin{array}{l}\text { In } \mathrm{CD} 3^{\text {hi }} \mathrm{ABC} \text { cases, PD-1/PD-L1 } \\
\text { interaction score+vs. - }\end{array}$ & $\begin{array}{l}(\mathrm{FDR}<0.10) \text { SMC4, CENPJ, RBCK1, SEC62, EPR1, YBX1, } \\
\text { SAR1A, MRPL37, DUS1L, SDHALP1, STK32C, FBXO36 }\end{array}$ & $\begin{array}{l}\text { PTCH1, ADAM21, RICS, ZFYVE16, LOC730102, } \\
\text { ST6GALNAC5, RAB3IP }\end{array}$ \\
\hline $\begin{array}{l}\text { In } \mathrm{CD}^{-} \mathrm{ABC} \text { cases, } \mathrm{PD}-\mathrm{L} 1^{+} \text {vs. PD- } \\
\mathrm{L}^{-}\end{array}$ & $\begin{array}{l}\text { (FDR < 0.20) RBPMS, RBMS1, CYP7B1, ITGB1, MYO1G, } \\
\text { LOC645984, CDRT1, LOC133874, TCTE3, IL8RB, PRDX3, } \\
\text { KPNA5, LOC283501, CALD1, ZNF436, ABHD5, PSG1, } \\
\text { TP53I11, MRGPRX2, EPHA3, COL2A1, KCNA1, PROK2, } \\
\text { PCDH10, C17orf78, PARK2, PON3, PAQR9, ATP1A2, ACSM5, } \\
\text { NDP, MEOX2, ITGBL1 }\end{array}$ & C17orf37, CDK5RAP3, SNRPC \\
\hline
\end{tabular}

$F D R$ false discovery rate, $A B C$ activated B-cell-like

*Fold change cutoffs were set for the sake of heatmap clarity

clinical effect of $\mathrm{T}$-cell $\mathrm{PD}-1^{+}$expression in $\mathrm{CD} 3^{\text {hi }}$ patients with diffuse large B-cell lymphoma, despite the association of $\mathrm{PD}-1^{+} \mathrm{CD}^{+}$expression with higher $\mathrm{CD}^{+}$ tissue cellularity. Irrespective of cell resource of PD-1 expression, total PD-1 tissue cellularity with a cutoff of $\geq 0.4 \%$ of tissue cellularity was also associated with significantly poorer overall survival after exclusion of $\mathrm{CD} 3^{-/ \mathrm{lo}}$ patients $(P=0.036$ for overall survival and $P=0.08$ for progression-free survival). Although T-cell PD- $1^{+}$expression was associated with higher PD-L1 ${ }^{+}$tissue cellularity, the adverse prognostic effect of $\mathrm{PD}-1^{+} \mathrm{CD} 3^{+}$expression in $\mathrm{CD} 3^{\text {hi }}$ patients was independent of PD-L1 expression and PD-1/PD-L1 interaction. Our gene expression profiling analysis showed that $\mathrm{PD}-1^{+} \mathrm{CD} 3^{+}$expression in patients with $\mathrm{PD}-\mathrm{L} 1^{+} / \mathrm{CD} 3^{\text {hi }}$ tissue cellularity was associated with upregulation of NFATC2a, a transcription factor of the NFAT family that is known to regulate $P D-1$ expression and terminal differentiation of $\mathrm{CD} 8^{+} \mathrm{T}$ cells $[5,31,32]$.

Prognostic analysis for the presence of PD-1/PD-L1 interaction (based on quantitative vicinity analysis for PD- $1^{+} \mathrm{CD}^{+}$ cells and PD-L1 ${ }^{+}$cells in the tissue) showed a greater adverse prognostic effect than that based on PD-1 or PD-L1 expression in the $\mathrm{CD} 3^{\text {hi }}$ patients overall and in the germinal center B-celllike and activated B-cell-like subgroups. These greater prognostic effects and identification of cases with a positive PD-1/
PD-L1 interaction score (albeit low) among cases with PD-1 ${ }^{-} \mathrm{CD} 3{ }^{\text {hi }}$ cellularity suggest that the PD-1/PD-L1 interaction score is a more sensitive and specific index for PD-1 inhibitory function than PD- $1^{+} \mathrm{CD}^{+}$cellularity. However, only a weak gene expression profiling signature was identified for PD-1/ PD-L1 interaction in the activated B-cell-like group, possibly because the major effect of PD-1/PD-L1 interaction is on signal transduction rather than transcriptional changes [33]. In addition, different from PD-1/PD-L1 expression, in patients with $\mathrm{CD}^{-/ \mathrm{lo}} / \mathrm{PD}-\mathrm{L1}^{+}$tissue cellularity, presence of PD-1/PDL1 interaction was associated with a significantly better survival, which could be attributable to the antitumor activity of $\mathrm{T}$ cells closely localized to tumors [19]. Also notably, an earlier study found that PD-L1 interacting with PD-1 or other unknown receptors on $\mathrm{T}$ cells promoted $\mathrm{T}$-cell infiltration and cytokine production in a murine chronic colitis model [34]. However, the favorable effect of PD-1/PD-L1 interaction in $\mathrm{CD}^{-/ \mathrm{lo}}$ patients was not significant in multivariate analysis, and we did not identify a gene signature associated with PD-1/ PD-L1 interaction in $\mathrm{CD}^{-/ \mathrm{lo}}$ patients.

Compared with earlier studies of tumor-cell PD-L1 expression in diffuse large B-cell lymphoma, this study extended the analysis to total PD-L1 ${ }^{+}$tissue cellularity, which can be conveniently quantified by fully automated methods. PD-L1 detected in this study could be expressed 
by tumor cells, antigen-presenting cells, $\mathrm{T}$ cells, or other cells in the tumor microenvironment. Tissue PD-L1 ${ }^{+}$ expression was associated with higher $\mathrm{CD}^{+}$tissue cellularity in the overall cohort and $\mathrm{CD} 3^{-/ \mathrm{lo}}$ and $\mathrm{CD} 3^{\text {lo }}$ cohorts and with a gene signature indicating active $\mathrm{T}$-cell responses in $\mathrm{CD} 3{ }^{\text {hi }}$ patients. Furthermore, we specifically showed that the adverse prognostic effect by total PD-L1 ${ }^{+}$cells was in $\mathrm{CD} 3^{\text {hi }}$ patients primarily but also in $\mathrm{CD} 3^{-/ \mathrm{lo}}$ cases without $\mathrm{MYC}^{+} \mathrm{BCL}_{2}^{+}$expression. The total frequency of these unfavorable PD-L1 ${ }^{+}$cases was $27 \%$. The adverse prognostic effect of tissue PD-L1 expression resembled that of tumor-cell PD-L1 expression by Kiyasu et al. [14] using a PD-L1/PAX5 double-staining technique, but the case numbers in this study was larger (414 vs. 273).

Furthermore, our results showed that PD-L1/PD-1 interaction was not the only underlying mechanisms for the poorer prognosis associated with PD-L1 expression, as in PD $-1^{-} \mathrm{CD} 3^{\text {hi }}$ cases without PD-L1 interaction with PD- $1^{+}$ $\mathrm{T}$ cells, PD-1 expression on non-T cells was not prognostic, whereas PD-L1 expression continued to show an adverse prognostic effect, which potentially could be attributable to the PD-L1-CD80 axis or other PD-1-independent inhibitory functions. Notably, PD-L1 $1^{+}$expression in these PD- $1^{-} \mathrm{CD} 3^{\text {hi }}$ cases having no PD-1/PD-L1 interaction was associated with a gene signature featuring macrophage-related genes. In addition, PD- $\mathrm{L}^{+}$expression in overall $\mathrm{CD} 3^{\text {hi }}$ cases was associated with upregulation of STATI (encoding a transcription factor which can activate $P D-L 1$ gene expression) and LILRB2 (whose expression can suppress macrophage function and phagocytosis [35]), and PD-L1 ${ }^{+}$expression in $\mathrm{CD}^{-}$patients was associated with upregulation of IL8RB (encoding a receptor for IL8, a chemokine produced by macrophages and other cells). Together, these results suggested that macrophage-related mechanisms may also be relevant to the PD-1-independent prognostic effect by PD-L1

+ expression, and that traditional evaluation of PD-L1 expression on tumor cells only is insufficient.

In addition, intrinsic tumor mechanisms may also contribute to the adverse prognostic effect of PD-L1 expression independent of PD-1, as we found that PD-L1 expression in $\mathrm{PD}-1^{-} \mathrm{CD} 3^{\text {hi }}$ cases was associated with higher tumor Myc protein expression relevant for the poorer survival. Notably, others have shown that Myc transcriptionally regulates PDL1 expression in a mouse model of MYC-induced T-cell acute lymphoblastic leukemia [36], whereas another study showed that BET/BRD4 (which regulates MYC transcription) upregulates PD-L1 expression independent of Myc in a Myc-driven B-cell lymphoma model [37]. Moreover, Myc also regulates expression of CD47, a critical "do not eat me" signals for macrophages [36]. Blocking anti-CD47 antibodies combined with rituximab have been shown to increase macrophage-mediated phagocytosis and antitumor $\mathrm{T}$-cell responses in preclinical studies, and induced clinical response (objective response rate, $40 \%$; complete response rate, $33 \%$ ) in patients with relapsed or refractory diffuse large B-cell lymphoma in a recent phase Ib clinical trial [38-40].

In summary, tissue PD-L1 expression and T-cell-specific PD-1 expression showed adverse prognostic effects secondary to that of low T cells in the tumor microenvironment, and PD1/PD-L1 interaction in tissue is essential but not always responsible for the inhibitory effect of PD-1 and PD-L1 expression in patients with $\mathrm{CD} 3^{\text {hi }}$ infiltrating diffuse large $\mathrm{B}$ cell lymphoma. These results provide rationales for immunotherapies promoting T-cell activation/infiltration in $\mathrm{CD}^{-/ \mathrm{lo}}$ patients and PD-1/PD-L1 blockade immunotherapies in patients with $\mathrm{CD} 3^{\text {hi }}$ tissue cellularity. However, PD-L1 ${ }^{+}$ expression does not always imply for PD-1 blockade immunotherapy, as in some PD-L1 ${ }^{+}$cases, PD-1-independent mechanisms are relevant for the poor prognosis. This study adds to our knowledge of the PD-1/PD-L1 axis in diffuse large B-cell lymphoma and has important implications for understanding the efficacy and biomarkers of PD-1/PD-L1 blockade therapies, as well as showed the clinical utility of automated immunofluorescent and quantitative analysis for prognostication and therapeutic decision. Notably, fluorescent multiplex immunohistochemistry has been implemented in clinical trials to characterize immune infiltrate in responders versus non-responders with solid cancers (for example, NCT03387761 and NCT03192202). However, further standardization and validation are warranted. In addition, the capacity of this simple three-antibody panel in prognostication in diffuse large B-cell lymphoma suggests that improvement of traditional chromogen-based immunohistochemistry and scoring methods in clinical practice in lieu of the availability of such specialized fluorescent multiplex immunohistochemistry and AQUA platform can also be valuable for patient stratification.

\section{Compliance with ethical standards}

Conflict of interest The authors declare that they have no conflict of interest.

Publisher's note: Springer Nature remains neutral with regard to jurisdictional claims in published maps and institutional affiliations.

\section{References}

1. Ishida Y, Agata Y, Shibahara K, Honjo T. Induced expression of PD-1, a novel member of the immunoglobulin gene superfamily, upon programmed cell death. EMBO J. 1992;11:3887-95.

2. Dong H, Zhu G, Tamada K, Chen LB7-H1. a third member of the B7 family, co-stimulates T-cell proliferation and interleukin-10 secretion. Nat Med. 1999;5:1365-9.

3. Latchman Y, Wood CR, Chernova T, et al. PD-L2 is a second ligand for PD-1 and inhibits $\mathrm{T}$ cell activation. Nat Immunol. 2001;2:261-8. 
4. Lesokhin AM, Ansell SM, Armand P, et al. Nivolumab in patients with relapsed or refractory hematologic alignancy: preliminary results of a phase Ib study. J Clin Oncol. 2016;34:2698-704.

5. Xu-Monette ZY, Zhang M, Li J, Young KH. PD-1/PD-L1 blockade: have we found the key to unleash the antitumor immuneresponse? Front Immunol. 2017;8:1597.

6. Xu-Monette ZY, Zhou J, Young KH. PD-1 expression and clinical PD-1 blockade in B-cell lymphomas. Blood. 2018;131:68-83.

7. Xerri L, Chetaille B, Serriari N, et al. Programmed death 1 is a marker of angioimmunoblastic T-cell lymphoma and B-cell small lymphocytic lymphoma/chronic lymphocytic leukemia. Hum Pathol. 2008;39:1050-8.

8. Muenst S, Hoeller S, Willi N, Dirnhofera S, Tzankov A. Diagnostic and prognostic utility of PD-1 in B cell lymphomas. Dis Markers. 2010;29:47-53.

9. Laurent C, Charmpi K, Gravelle P, et al. Several immune escape patterns in non-Hodgkin's lymphomas. Oncoimmunology. 2015;4: e1026530.

10. Ahearne MJ, Bhuller K, Hew R, et al. Expression of PD-1 (CD279) and FoxP3 in diffuse large B-cell lymphoma. Virchows Arch. 2014;465:351-8.

11. Fang X, Xiu B, Yang Z, et al. The expression and clinical relevance of PD-1, PD-L1, and TP63 in patients with diffuse large Bcell lymphoma. Medicine (Baltim). 2017;96:e6398.

12. Kwon D, Kim S, Kim PJ, et al. Clinicopathological analysis of programmed cell death 1 and programmed cell death ligand 1 expression in the tumour microenvironments of diffuse large B cell lymphomas. Histopathology. 2016;68:1079-89.

13. Cohen M, Vistarop AG, Huaman F, et al. Cytotoxic response against Epstein Barr virus coexists with diffuse large B-cell lymphoma tolerogenic microenvironment: clinical features and survival impact. Sci Rep. 2017;7:10813.

14. Kiyasu J, Miyoshi H, Hirata A, et al. Expression of programmed cell death ligand 1 is associated with poor overall survival in patients with diffuse large B-cell lymphoma. Blood. 2015;126:2193-201.

15. Xing W, Dresser K, Zhang R, et al. PD-L1 expression in EBVnegative diffuse large B-cell lymphoma: clinicopathologic features and prognostic implications. Oncotarget. 2016;7:59976-86.

16. Menter T, Bodmer-Haecki A, Dirnhofer S, Tzankov A. Evaluation of the diagnostic and prognostic value of PDL1 expression in Hodgkin and B-cell lymphomas. Hum Pathol. 2016;54:17-24.

17. Rossille D, Azzaoui I, Feldman AL, et al. Soluble programmed death-ligand 1 as a prognostic biomarker for overall survival in patients with diffuse large B-cell lymphoma: a replication study and combined analysis of 508 patients. Leukemia. 2017;31:988-91.

18. Tumeh PC, Harview CL, Yearley JH, et al. PD-1 blockade induces responses by inhibiting adaptive immune resistance. Nature. 2014;515:568-71.

19. Carstens JL, Correa de Sampaio P, Yang D, et al. Spatial computation of intratumoral $\mathrm{T}$ cells correlates with survival of patients with pancreatic cancer. Nat Commun. 2017;8:15095.

20. Carey CD, Gusenleitner D, Lipschitz M, et al. Topological analysis reveals a PD-L1-associated microenvironmental niche for ReedSternberg cells in Hodgkin lymphoma. Blood. 2017;130:2420-30.

21. Dolled-Filhart M, Gustavson M, Camp RL, et al. Automated analysis of tissue microarrays. Methods Mol Biol. 2010;664:151-62.

22. Johnson DB, Bordeaux JM, Kim JY, et al. Quantitative spatial profiling of PD-1/PD-L1 interaction and HLA-DR/IDO-1 predicts improved outcomes of anti-PD-1 therapies in metastatic melanoma. Clin Cancer Res. 2018;24:5250-60.

23. Xu-Monette ZY, Li L, Byrd JC, et al. Assessment of CD37 B-cell antigen and cell of origin significantly improves risk prediction in diffuse large B-cell lymphoma. Blood. 2016;128:3083-3100.
24. Visco C, Li Y, Xu-Monette ZY, et al. Comprehensive gene expression profiling and immunohistochemical studies support application of immunophenotypic algorithm for molecular subtype classification in diffuse large B-cell lymphoma: a report from the International DLBCL Rituximab-CHOP Consortium Program Study. Leukemia. 2012;26:2103-13.

25. Xu-Monette ZY, Dabaja BS, Wang X, et al. Clinical features, tumor biology, and prognosis associated with MYC rearrangement and Myc overexpression in diffuse large B-cell lymphoma patients treated with rituximab-CHOP. Mod Pathol. 2015;28:1555-73.

26. $\mathrm{Hu} \mathrm{S}, \mathrm{Xu}-$ Monette $\mathrm{ZY}$, Tzankov A, et al. MYC/BCL2 protein coexpression contributes to the inferior survival of activated B-cell subtype of diffuse large B-cell lymphoma and demonstrates highrisk gene expression signatures: a report from The International DLBCL Rituximab-CHOP Consortium Program. Blood. 2013; 121:4021-31.

27. Hu S, Xu-Monette ZY, Balasubramanyam A, et al. CD30 expression defines a novel subgroup of diffuse large B-cell lymphoma with favorable prognosis and distinct gene expression signature: a report from the International DLBCL RituximabCHOP Consortium Program Study. Blood. 2013;121:2715-24.

28. Butte MJ, Keir ME, Phamduy TB, Sharpe AH, Freeman GJ. Programmed death-1 ligand 1 interacts specifically with the B7-1 costimulatory molecule to inhibit $\mathrm{T}$ cell responses. Immunity. 2007;27:111-22.

29. Paust S, Lu L, McCarty N, Cantor H. Engagement of B7 on effector $\mathrm{T}$ cells by regulatory $\mathrm{T}$ cells prevents autoimmune disease. Proc Natl Acad Sci USA. 2004;101:10398-403.

30. Park JJ, Omiya R, Matsumura Y, et al. B7-H1/CD80 interaction is required for the induction and maintenance of peripheral $\mathrm{T}$-cell tolerance. Blood. 2010;116:1291-8.

31. Philip M, Fairchild L, Sun L, et al. Chromatin states define tumour-specific T cell dysfunction and reprogramming. Nature. 2017;545:452-6.

32. Pauken KE, Sammons MA, Odorizzi PM, et al. Epigenetic stability of exhausted $\mathrm{T}$ cells limits durability of reinvigoration by PD-1 blockade. Science. 2016;354:1160-5.

33. Mognol GP, Spreafico R, Wong V, et al. Exhaustion-associated regulatory regions in CD8+ tumor-infiltrating T cells. Proc Natl Acad Sci USA. 2017;114:E2776-E2785.

34. Kanai T, Totsuka T, Uraushihara K, et al. Blockade of B7-H1 suppresses the development of chronic intestinal inflammation. $\mathrm{J}$ Immunol. 2003;171:4156-63.

35. Barkal AA, Weiskopf K, Kao KS, et al. Engagement of MHC class I by the inhibitory receptor LILRB1 suppresses macrophages and is a target of cancer immunotherapy. Nat Immunol. 2017;19:76-84.

36. Casey SC, Tong $\mathrm{L}, \mathrm{Li} \mathrm{Y}$, et al. MYC regulates the antitumor immune response through CD47 and PD-L1. Science. 2016;352: 227-31.

37. Hogg SJ, Vervoort SJ, Deswal S, et al. BET-bromodomain inhibitors engage the host immune system and regulate expression of the immune checkpoint ligand PD-L1. Cell Rep. 2017;18: 2162-74.

38. Chao MP, Alizadeh AA, Tang C, et al. Anti-CD47 antibody synergizes with rituximab to promote phagocytosis and eradicate non-Hodgkin lymphoma. Cell. 2010;142:699-713.

39. Tseng D, Volkmer JP, Willingham SB, et al. Anti-CD47 antibodymediated phagocytosis of cancer by macrophages primes an effective antitumor T-cell response. Proc Natl Acad Sci USA. 2013;110:11103-8.

40. Advani R, Flinn I, Popplewell L, et al. CD47 blockade by Hu5F9G4 and rituximab in non-Hodgkin's lymphoma. N Engl J Med. 2018;379:1711-21. 


\section{Affiliations}

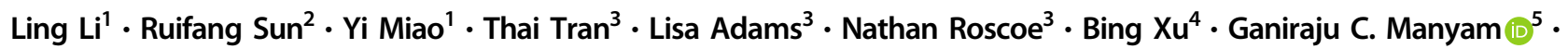
Xiaohong $\operatorname{Tan}^{1} \cdot$ Hongwei Zhang ${ }^{1} \cdot$ Min Xiao $^{1} \cdot$ Alexandar Tzankov $^{6}{ }^{6} \cdot$ Carlo Visco $^{7}{ }^{7} \cdot$ Karen Dybkaer $^{8}$.

Govind Bhagat $^{9} \cdot$ Wayne Tam ${ }^{10}$. Eric D. Hsi ${ }^{11} \cdot$ J. Han van Krieken ${ }^{12} \cdot$ Hua You $^{13} \cdot$ Jooryung Huh $^{14} \cdot$ Maurilio Ponzoni $^{15}$. Andrés J. M. Ferreri ${ }^{15}$. Michael B. Møller $\mathbb{D}^{16} \cdot$ Miguel A. Piris $^{17} \cdot$ Mingzhi Zhang $^{18} \cdot$ Jane N. Winter $^{19} \cdot$ L. Jeffrey Medeiros $^{1} \cdot$

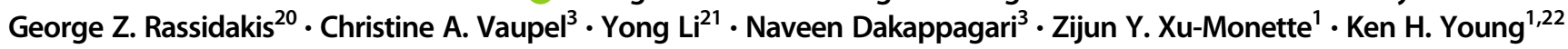

1 Department of Hematopathology, The University of Texas MD Anderson Cancer Center, Houston, TX, USA

2 Department of Pathology, Shanxi Cancer Hospital, Taiyuan, Shanxi, China

3 Navigate BioPharma Services, Inc., a Novartis subsidiary, Carlsbad, CA, USA

4 Department of Hematology, The First Affiliated Hospital of Xiamen University, Fujian, China

5 Department of Bioinformatics and Computational Biology, The University of Texas MD Anderson Cancer Center,

Houston, Texas, USA

6 Department of Histopathology, University Hospital of Basel, Basel, Switzerland

7 San Bortolo Hospital, Vicenza, Italy

8 Aalborg University Hospital, Aalborg, Denmark

9 New York-Presbyterian/Columbia University Medical Center, New York, NY, USA

10 Weill Cornell Medicine, Cornell University, New York, NY, USA

11 Department of Pathology, Cleveland Clinic, Cleveland, OH, USA
12 Radboud University Medical Centre, Nijmegen, Netherlands

13 Affiliated Cancer Hospital \& Institute of Guangzhou Medical University, Guangzhou, China

14 Asan Medical Center, University of Ulsan College of Medicine, Seoul, Korea

15 San Raffaele H. Scientific Institute, Milan, Italy

16 Odense University Hospital, Odense, Denmark

17 Marqués de Valdecilla University Hospital, Santander, Spain

18 Department of Oncology, The First Affiliated Hospital Zhengzhou University, Zhengzhou, China

19 Feinberg School of Medicine, Northwestern University, Chicago, IL, USA

20 Karolinska Institutet, Karolinska University Hospital, Solna, Sweden

21 Department of Cancer Biology, Lerner Research Institute, Cleveland Clinic, Cleveland, $\mathrm{OH}$, USA

22 Graduate School of Biomedical Sciences, The University of Texas Health Science Center at Houston, Houston, TX, USA 